Article

\title{
Numerical Investigation into the Effect of Natural Fracture Density on Hydraulic Fracture Network Propagation
}

\author{
Zhaohui Chong ${ }^{1,2}$, Xuehua $\mathrm{Li}^{1, *} \mathbb{D}$, Xiangyu Chen ${ }^{1}$, Ji Zhang ${ }^{3}$ and Jingzheng $\mathrm{Lu}^{1}$ \\ 1 Key Laboratory of Deep Coal Resource, Ministry of Education of China, School of Mines, \\ China University of Mining and Technology, Xuzhou 221116, China; chongzhaohui2003@126.com (Z.C.); \\ 18952263095@163.com (X.C.); 13641549506@163.com (J.L.) \\ 2 Faculty of Engineering and Information Sciences, University of Wollongong, Wollongong 2522, Australia \\ 3 Beijing Computational Science Research Center, Beijing 100193, China; gotofd@gmail.com \\ * Correspondence: xuehua_cumt@163.com; Tel.: +86-15651359163
}

Received: 3 April 2017; Accepted: 26 June 2017; Published: 3 July 2017

\begin{abstract}
Hydraulic fracturing is an important method to enhance permeability in oil and gas exploitation projects and weaken hard roofs of coal seams to reduce dynamic disasters, for example, rock burst. It is necessary to fully understand the mechanism of the initiation, propagation, and coalescence of hydraulic fracture network (HFN) caused by fluid flow in rock formations. In this study, a coupled hydro-mechanical model was built based on synthetic rock mass (SRM) method to investigate the effects of natural fracture (NF) density on HFN propagation. Firstly, the geometrical structures of NF obtained from borehole images at the field scale were applied to the model. Secondly, the micro-parameters of the proposed model were validated against the interaction between NF and hydraulic fracture (HF) in physical experiments. Finally, a series of numerical simulations were performed to study the mechanism of HFN propagation. In addition, confining pressure ratio (CPR) and injection rate were also taken into consideration. The results suggested that the increase of $\mathrm{NF}$ density drives the growth of stimulated reservoir volume (SRV), concentration area of injection pressure (CAIP), and the number of cracks caused by NF. The number of tensile cracks caused by rock matrix decrease gradually with the increase of NF density, and the number of shear cracks caused by rock matrix are almost immune to the change of NF density. The propagation orientation of HFN and the breakdown pressure in rock formations are mainly controlled by CPR. Different injection rates would result in a relatively big difference in the gradient of injection pressure, but this difference would be gradually narrowed with the increase of NF density. Natural fracture density is the key factor that influences the percentages of different crack types in HFN, regardless of the value of CPR and injection rate. The proposed model may help predict HFN propagation and optimize fracturing treatment designs in fractured rock formations.
\end{abstract}

Keywords: hydro-mechanical coupling; SRM-based fracturing model; breakdown pressure; crack type; confining pressure ratio (CPR); injection rate

\section{Introduction}

Hydraulic fracturing is an important method used to enhance oil and gas production in horizontal wells [1,2]. It can form hydraulic fracture networks (HFNs), along with natural fractures (NFs), in rock formations to areas far away from horizontal wells. The purpose of hydraulic fracturing is to stimulate the permeability of rock formations, and allow oil and gas to permeate into horizontal wells $[3,4]$. In addition, a hard roof often leads to the danger of a hanging roof in the coal mining process, which, in turn, may result in dynamic disasters, such as rock burst $[5,6]$. The most important solution is using 
hydraulic fracturing to weaken a hard roof. Therefore, it is important to investigate the effects of NF on HFN propagation.

Natural fractures are a kind of pre-existing flaw in rock formations, which determine the propagation trajectory of HFN in hydraulic fracturing (HF). The interaction between NF and HF has been widely investigated by many scholars [7-9]. Renshaw and Pollard [10] proposed a simple criterion to identify crack propagation orientation during the mutually perpendicular interaction between NF and HF, and verified this criterion through physical experiments. Gu and Weng [11] further developed Renshaw's criterion and used the updated criterion to analyze non-orthogonal intersections between NF and HF.

The interaction between NFs and HFs in hydraulic fracturing can be divided into following six scenarios (Figure 1a,b) [10,12,13]:

(1) Hydraulic fracturing directly crosses a NF (Figure 1c). Hydraulic fracturing can cross NFs easily when NFs have relatively strong cohesion, or the rock formations bear high confining stress. In this case, the interaction interface opens with tension and the HF propagates along the same orientation with strong stress on the HF tip.

(2) Hydraulic fracturing intersecting a NF (Figure 1d). When a HF crosses with a NF, fluid flows into the NF, but the HF does not initiate on the interface because of a non-existing weak face. With the increase of fluid, the HF crosses the NF and propagates along the same orientation as before. As a result, they form T-shaped branches.

(3) Hydraulic fracturing crossing with an offset (Figure 1e). When a HF interacts with a NF, a small offset occurs due to the stress concentration caused by localized interface separation and shear slip.

(4) Hydraulic fracturing arrested by a NF (Figure 1f). When the strength of a NF is far smaller than that of the rock matrix, and the formations bear little confining pressure, the HF is arrested by the NF and cannot sufficiently transmit the NF because the interface fails in shear and slips.

(5) Hydraulic fracturing shear slipping along a NF (Figure 1g). When the fluid pressure in a HF is smaller than the closure stress of a NF, the interface would be separated because of shear stress. The fluid permeability in the NF would be enlarged, leading to shear cracks propagating along the interface.

(6) Hydraulic fracturing branching or turning at end of an NF (Figure 1h). When fluid pressure exceeds the closure stress of the interface, the NF would be widened by excessive tensile stress and allow fluid to flow in. Consequently, the NF would become a branch of the HFN. In addition, the concentration of fluid pressure would result in another HF initiation at the end of the NF.

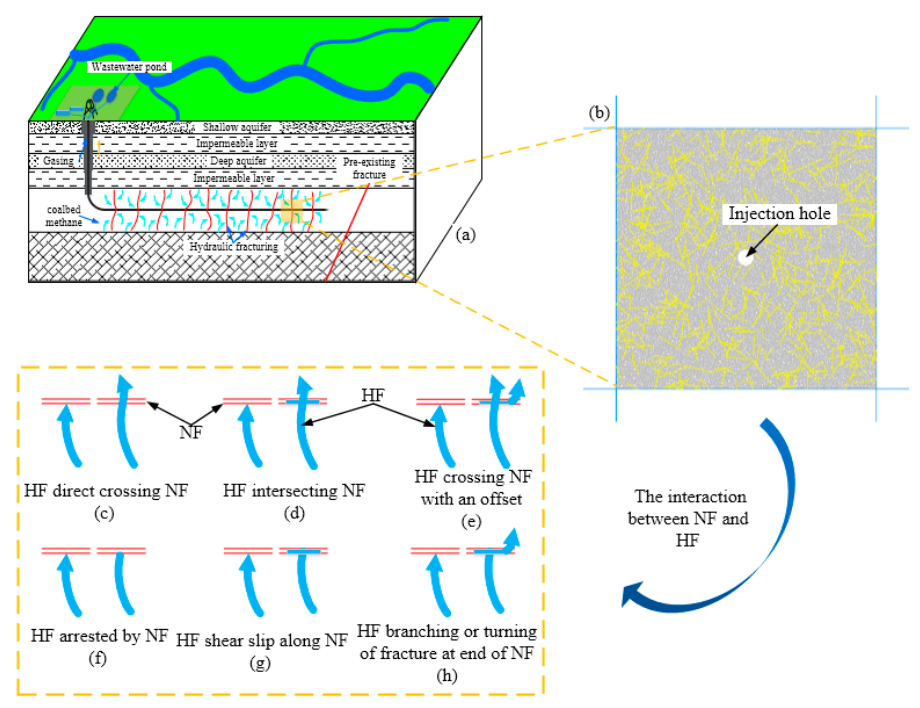

Figure 1. Geometry of a hydraulic fracture network (HFN) depicting various scenarios of interaction with natural fractures (NFs). 
All the aforementioned scenarios assumed that the formations only have one NF. They are, however, abundant in real hydraulic fracturing process. In order to deal with this weakness, scholars proposed a discrete fracture network (DFN) model [14-18]. A discrete fracture network is a network consisting of abundant discrete NFs, which distribute certain criteria. Liu et al. [19] evaluated nine factors affecting the equivalent permeability in a two-dimensional DFN model based on the mathematical formula. Huang et al. [20], who established a three-dimensional DFN model and compared it with the two-dimensional DFN model, also studied on factors affecting their equality. Meyer and Bazan [21] used an elliptical region containing two groups of parallel and uniformly spaced vertical fractures along directions of horizontal principal stress to represent the HFN in hydraulic fracturing. Weng et al. $[13,22]$ built a special fracture model and studied the interaction criterion between NFs and HFs.

With these models, they successfully simulated the interactions between NFs and HFs. In addition, other numerical methods were also adopted to study HFNs in rock formations, including the boundary element method (BEM) [23,24], extended finite element method (XFEM) [25,26], and rock failure process analysis (RFPA) $[27,28]$. The synthetic rock mass (SRM) method is one of many discrete element methods (DEMs), which is widely used to simulate the crack initiation, propagation, and coalescence in rock formations [29,30]. In this model, rock mass is represented by an assembly of particles bound together, and pre-existing fractures are represented by DFN. In this model, the spatial properties of the fractures, obtained from geological statistics, are used as the input parameters of DFN. Although the models mentioned above can be used to study fractured rock formations, there are still many difficulties and challenges-the NF density influences the propagation of HFN in hydraulic fracturing is still unclear. Therefore, it is necessary to build a coupled hydro-mechanical model in fractured rock formations to investigate this issue.

In this paper, a SRM-based fracturing model is proposed to study the propagation of HFN in fractured rock formations. First, the geometrical structure of HFs used in this model was obtained from the statistical results of borehole images. Second, the micro-parameters of the model were calibrated through physical experiments that studied the interaction between NF and HF. The breakdown pressure of the model under different confining pressures was also compared with theoretical equations. Finally, a set of numerical simulations were performed to investigate the effects of NF density on HFN propagation. Additionally, external factors like confining pressure ratio (CPR) and injection rate were also considered.

\section{Model Description}

\subsection{Synthetic Rock Mass (SRM) Method}

SRM method is considered as a proper model to study natural fracture (NF) in particle assemblies [31]. Although SRM is a discontinuum method, particles can still bound together with the parallel bond method to simulate rock deformations. Tensile or shear cracks can initiate when the bonds between particles are broken. The movement and deformation of particles can influence the macro mechanical behavior of the model. Figure 2 shows contacts between particles, of which the force and force moment can be divided into two components [32]:

$$
\begin{gathered}
\bar{F}_{i}=\bar{F}^{\mathbf{n}} n_{i}+\bar{F}^{\mathrm{s}} t_{i} \\
\bar{M}_{i}=\bar{M}^{\mathbf{n}} n_{i}+\bar{M}^{\mathrm{s}} t_{i}
\end{gathered}
$$

where $\bar{F}_{i}, \bar{F}^{\mathbf{n}}$, and $\bar{F}^{\mathrm{s}}$ are the total, normal-, and shear-directed force exerted by the parallel bond, respectively; $\bar{M}_{i}, \bar{M}^{\mathrm{n}}$, and $\bar{M}^{\mathrm{s}}$ are the total, normal-, and shear-directed moment exerted by the parallel bond, respectively; and $n_{i}$ and $t_{i}$ are normal- and shear-directed unit vectors, respectively. 


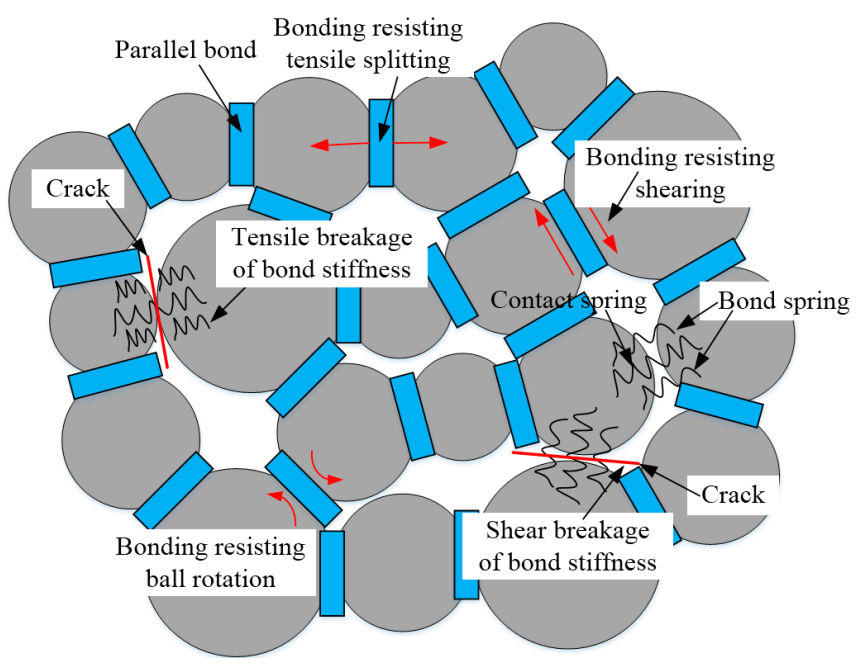

Figure 2. The parallel bond and its breaks of inter-particle bond in SRM [32].

Friction coefficient $\mu_{p b}$ of the contact between two particles is defined as:

$$
\bar{F}^{s} \leq \mu_{p b} \bar{F}^{n}
$$

The increments of contact force and force moment are represented as:

$$
\begin{gathered}
\Delta \bar{F}^{\mathbf{n}}=\bar{k}^{\mathbf{n}} A \Delta U^{\mathbf{n}} \\
\Delta \bar{F}^{\mathbf{s}}=-\bar{k}^{\mathbf{s}} A \Delta U^{\mathbf{s}} \\
\Delta \bar{M}^{\mathbf{n}}=-\bar{k}^{\mathbf{s}} I \Delta \theta^{\mathbf{n}} \\
\Delta \bar{M}^{\mathbf{s}}=-\bar{k}^{\mathbf{n}} I \Delta \theta^{\mathbf{s}}
\end{gathered}
$$

where $\Delta \bar{F}^{n}$ and $\Delta \bar{F}^{s}$ are the increments of normal- and shear-directed force, respectively; $\bar{k}^{n}$ and $\bar{k}^{s}$ are the contact normal and shear stiffness, respectively; $\Delta U^{n}$ and $\Delta U^{s}$ are the increments of elastic force, which are added to current value; $A$ and $I$ are the area and moment of inertia of parallel bond cross section; $\Delta \bar{M}^{n}$ and $\Delta \bar{M}^{s}$ are the increments of normal- and shear-directed moment, respectively; and $\Delta \theta^{n}$ and $\Delta \theta^{s}$ are the increments of rotational angle which are added to the current value.

The tensile and shear strengths on particle contacts can be calculated with the following equations:

$$
\begin{aligned}
& \bar{\sigma}^{\max }=\frac{-\bar{F}^{n}}{A}+\frac{\left|\bar{M}^{s}\right| \bar{R}}{I} \\
& \bar{\tau}^{\max }=\frac{\left|\bar{F}^{s}\right|}{A}+\frac{\left|\bar{M}^{n}\right| \bar{R}}{J}
\end{aligned}
$$

where $\bar{\sigma}^{\max }$ and $\bar{\tau}^{\max }$ are the tensile and shear strength, respectively; $J$ is polar moment of inertia of the parallel bond cross section, respectively.

SRM method is built by inserting discrete fracture network (DFN) into the adopted particle assembly. In the model, the NF is represented by smooth joint (SJ) logic (Figure 3). A SJ is used in SRM to simulate the crack development in rock mass [33]. Once the joint plane is defined, the SJ would be distributed on the contacts between particles (Figure 3a). Each joint plane consists of two overlapping surfaces-Surface $A$ and Surface $B$-particles can only move along these two 
surfaces (Figure $3 b$ ). The orientations of these surfaces are represented by joint unit normal vector $\hat{\mathbf{n}}_{j}$ which is defined through joint dip angle $\theta_{p}$.

$$
\hat{\mathbf{n}}_{j}=\left(\sin \theta_{p}, \cos \theta_{p}\right)
$$

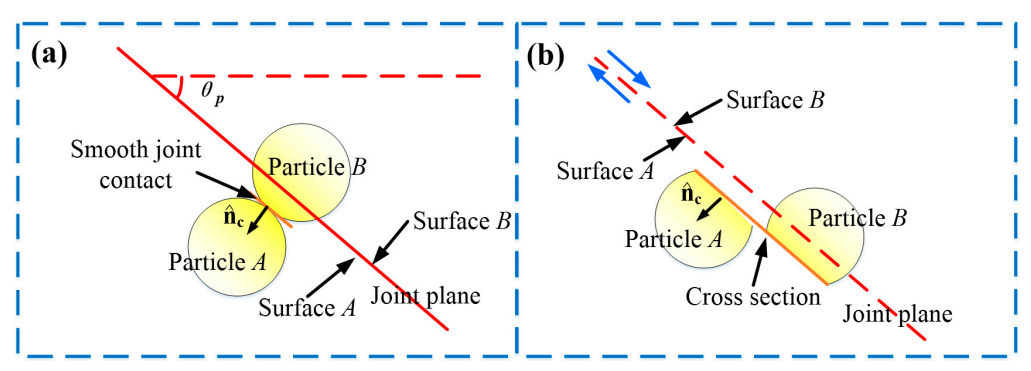

Figure 3. Smooth joint (SJ) contact model in two dimensions.

The dot product of $\hat{\mathbf{n}}_{j}$ and contact unit normal vector $\hat{\mathbf{n}}_{c}$ are applied to determine the surface each particle lies. If $\hat{\mathbf{n}}_{j} \cdot \hat{\mathbf{n}}_{c}>0$, the particle lies in the nearer surface, such as Ball $A$ lies in Surface $A$ (Figure 3a). The existing bonds are removed to build $\mathrm{SJ}$ between particles. They are just like a set of elastic springs evenly distributed among the cross sections among particles. The area of SJ cross section $A^{\prime}$ is defined as:

$$
A^{\prime}=\pi \bar{R}^{2}
$$

The average radius $\bar{R}$ is defined as:

$$
\bar{R}=\bar{\lambda} \min \left(R^{A}, R^{B}\right)
$$

The force vector $\mathbf{F}$ and displacement vector $\mathbf{U}$ of $\mathbf{S J}$ on the local coordinates of the joint plane are defined as:

$$
\begin{aligned}
\mathbf{F} & =F_{n} \hat{\mathbf{n}}_{j}+\mathbf{F}_{\mathbf{s}} \\
\mathbf{U} & =U_{n} \hat{\mathbf{n}}_{j}+\mathbf{U}_{\mathbf{s}}
\end{aligned}
$$

where $F_{n}$ and $\mathbf{F}_{\mathbf{s}}$ are normal force and shear force vectors of SJ, respectively, and $U_{n}$ and $\mathbf{U}_{\mathbf{s}}$ are normal relative displacement and shear relative displacement vectors of SJ.

The mechanical behavior of SJ follows the Coulomb sliding model, and the relative displacement increment of two particles interacting with each other in each time step is divided into two parts: normal and shear component. The normal and shear force of the SJ are updated using the following equations (Figure 4):

$$
\begin{aligned}
& F_{n}:=F_{n}+s j_{-} k_{n} A \Delta U^{e}{ }_{n} \\
& \mathbf{F}_{\mathbf{s}}^{\prime}:=\mathbf{F}_{\mathbf{s}}-s j_{-} k_{s} A \Delta \mathbf{U}^{\mathbf{e}}{ }_{\mathbf{s}}
\end{aligned}
$$

where $\bar{k}_{n j}$ and $\bar{k}_{s j}$ are the normal and shear stiffness of SJ, respectively. $\Delta$ is an increment of the updated value. Maximum shear force $F_{s}^{*}$ is determined by friction coefficient $\mu_{j}$ of the SJ, defined as:

$$
F_{s}^{*}=F_{n} \mu_{j}
$$

If $\left|\mathbf{F}_{\mathbf{s}}^{\prime}\right| \leq F_{s}^{*}$, then $\left|\mathbf{F}_{\mathbf{s}}\right| \leq\left|\mathbf{F}_{\mathbf{s}}^{\prime}\right|$; otherwise, sliding displacement will occur, then $\left|\mathbf{F}_{\mathbf{s}}\right|=F_{s}^{*}$ (Figure 4b). 


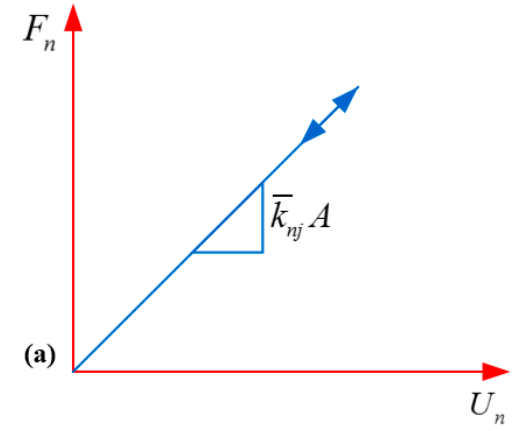

Figure 4. Smooth joint force-displacement law (b) shear force versus shear displacement.

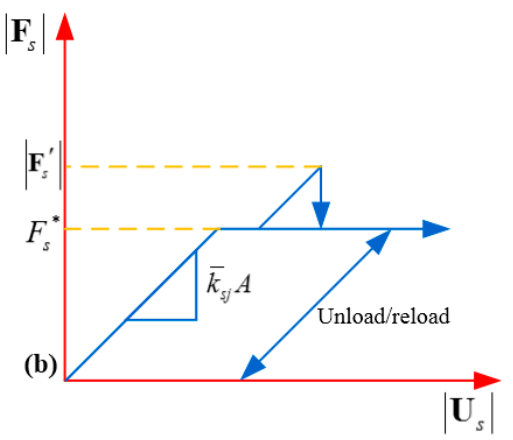

(a) normal force versus normal displacement;

\subsection{Hydro-Mechanical Coupling in SRM}

In SRM, the polygons formed through the contacts between particles are called fluid domains. Viscous fluid flow is based on the assumption that fluid domains are connected with fluid flow channels which refers to a series of contacts in particle assembly. Each fluid domain has its own volume which can be calculated by blue surrounding lines linking particle centers (Figure 5a). The fluid flow is driven by the pressure formed at the two ends of a fluid flow channel (Figure $5 c-e$ ). The fluid flow is controlled by Poiseuille equation which assumes that the fluid flow is laminar within the channel. Therefore, the volumetric flow rate $Q$ can be defined as:

$$
Q=\frac{a^{3}}{12 \mu} \frac{\Delta P}{L}
$$

where $\mu$ is the fluid dynamic viscosity; $\Delta P$ is fluid pressure difference between the two neighboring domains; $\mathrm{L}$ and $a$ are the length and aperture of the flow channel, respectively.

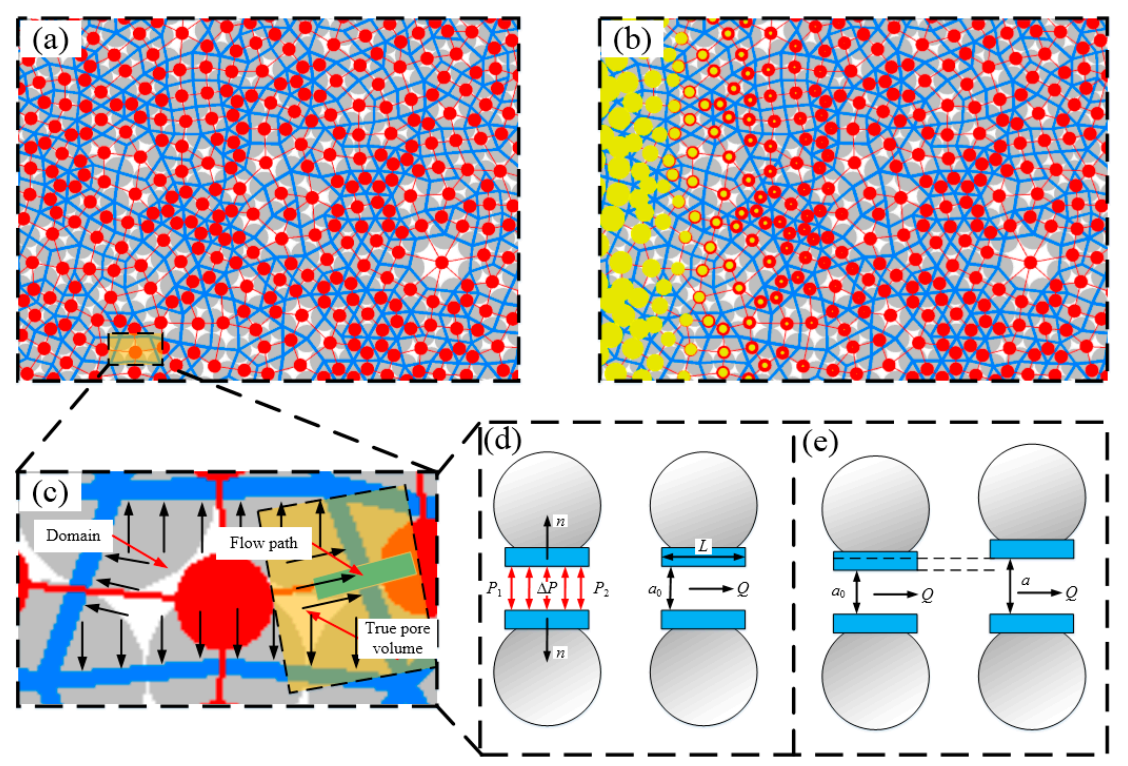

Figure 5. Synthetic rock mass (SRM) method used in coupled hydro-mechanical simulation (a) fluid domains (blue polygons), centers of domains (red circles), and flow pipes (red lines) composing the fluid network; (b) distribution of fluid pressure; (c) domain and flow channel; (d) fluid pressure build up; (e) change of aperture. 
Figure $5 \mathrm{~b}$ demonstrates that the fluid pressure (yellow spots) formed in the rock mass and the size of the spot is positively correlated to the magnitude of the pressure. In the calculation of fluid flow, the change of fluid domain volume was not taken into consideration in previous works to simplify hydro-mechanical coupling $[34,35]$. The change, however, was considered in this paper. The increment of fluid pressure $\Delta P$ in the fluid domain can be calculated with the following equation:

$$
\Delta P=\frac{K_{f}}{V_{d}}\left(\sum Q \cdot \Delta t-\Delta V_{d}\right)
$$

where $K_{f}$ is the fluid bulk modulus; $\Delta t$ is the increments of time step; $V_{d}$ is the pore volume; $\Delta V_{d}$ is the change of value in the pore volume.

Deformation of fluid domain is caused by the particle contact pressure, which in turn, leads to the deformation of whole rock mass. Consequently, the deformation of rock mass would drive the change of the contact force between particles. Cracks can initiate once contact stress exceeds the maximum tensile or shear stress in Equation (8) or Equation (9). In the proposed model, the aperture of the fluid channel can be calculated with an equation related to normal stress. An empirical equation has been adopted to describe the relationship between laminated pipe aperture and normal stress [36].

$$
a=a_{\mathrm{inf}}+\left(a_{z e o}-a_{\mathrm{inf}}\right) e^{\xi^{\tau} \sigma_{n}}
$$

where $a_{\text {inf }}$ and $a_{z e o}$ are the aperture value at infinite and zero normal stress, respectively; coefficient $\xi$ is the speed of aperture decay with the increasing of $\sigma_{n}$ and usually equals -0.15 [37]. The units of $a_{\mathrm{inf}}$ and $a_{z e o}$ are ' $\mathrm{m}$ '; the units of $\sigma_{n}$ is 'MPa'; coefficient $\xi$ does not have any units.

When $\sigma_{n}$ approaches infinity, $a_{z e o}$ would be infinitely close to $a_{\text {inf. }}$. The values of $a_{z e o}$ and $a_{\text {inf }}$ are defined as Equation (21) [34]:

$$
k=\frac{1}{12 V} \sum_{\text {pipes }} L a^{3}
$$

where $k$ and $V$ are the permeability and the total volume of rock mass.

Once a crack initiates, the aperture of the fluid flow channel tends to be infinite, which may cause the problem of computational instability. Simulating the fluid flow between domains, which causes initiation of cracks, is vital to hydraulic fracturing. The cracks caused by the bond breakage between two particles can lead to instantaneous fluid flow. Fluid pressures $P_{f}^{\prime}$ in the two domains, after bond breakage, are considered as equivalent to the average of the pressures before bond breakage (Figure 6) [34,35,38]. The updated fluid pressure calculation equation is defined as:

$$
P_{f}^{\prime}=\frac{P_{f A}+P_{f B}}{2}
$$

where $P_{f A}$ and $P_{f B}$ are fluid pressures, related to Domain $A$ and Domain $B$ in Figure 6, respectively.

This equation is not applicable when there is a large difference between two domain volumes. Therefore, once cracks initiate, the fluid pressure in the two related domains can be calculated through the following equation [39]:

$$
P_{f}^{\prime}=\left[\frac{V_{f A}+V_{f B}}{\left(V_{0 A}+V_{0 B}\right) \varphi}-1\right] K_{f}
$$

where $\varphi$ is the model porosity; $V_{f A}$ and $V_{f B}$ are the volumes of fluids existing in Domain $A$ and Domain $B$, respectively, and are shown in Figure 6; $V_{0 A}$ and $V_{0 B}$ are the volumes of Domain $A$ and Domain $B$, respectively. 


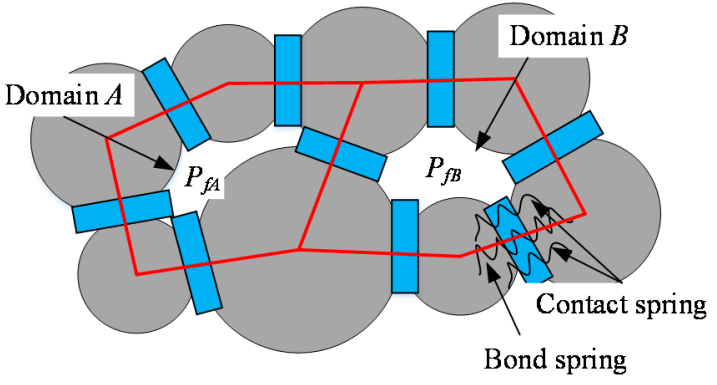

(a)

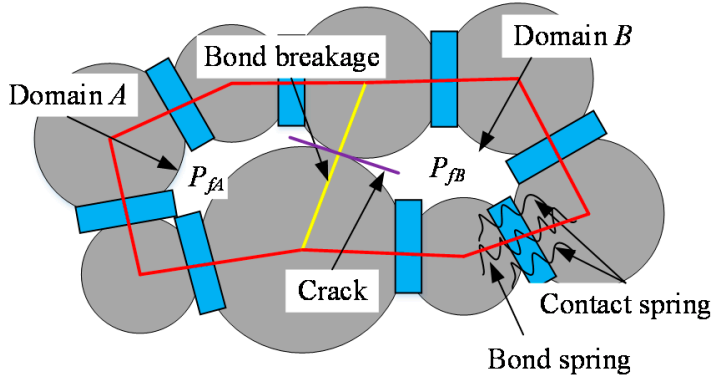

(b)

Figure 6. Bond breakage and fluid pressure balancing according to Equation (23) in the two domains:

(a) fluid pressure before a crack initiation and (b) fluid pressure after a crack initiation.

The modeling procedures of a hydro-mechanically coupled system is demonstrated in Figure 7. The deformation of rock formations would result in the change of fluid domain volume. At the same time, the aperture of the fluid flow channel would also change based on the change of particle contact stress. Because the fluid pressure is exerted on particle contact in the domain, the rock deformation and particle contact force can change at every time increment. In addition, a HFN consists of four types of cracks-namely, tensile crack of rock matrix (TCRM), shear crack of rock matrix (SCRM), tensile crack caused by natural fracture (TCNF), and shear crack caused by natural fracture (SCNF) - each of these were identified by an independent sub-program in this study.

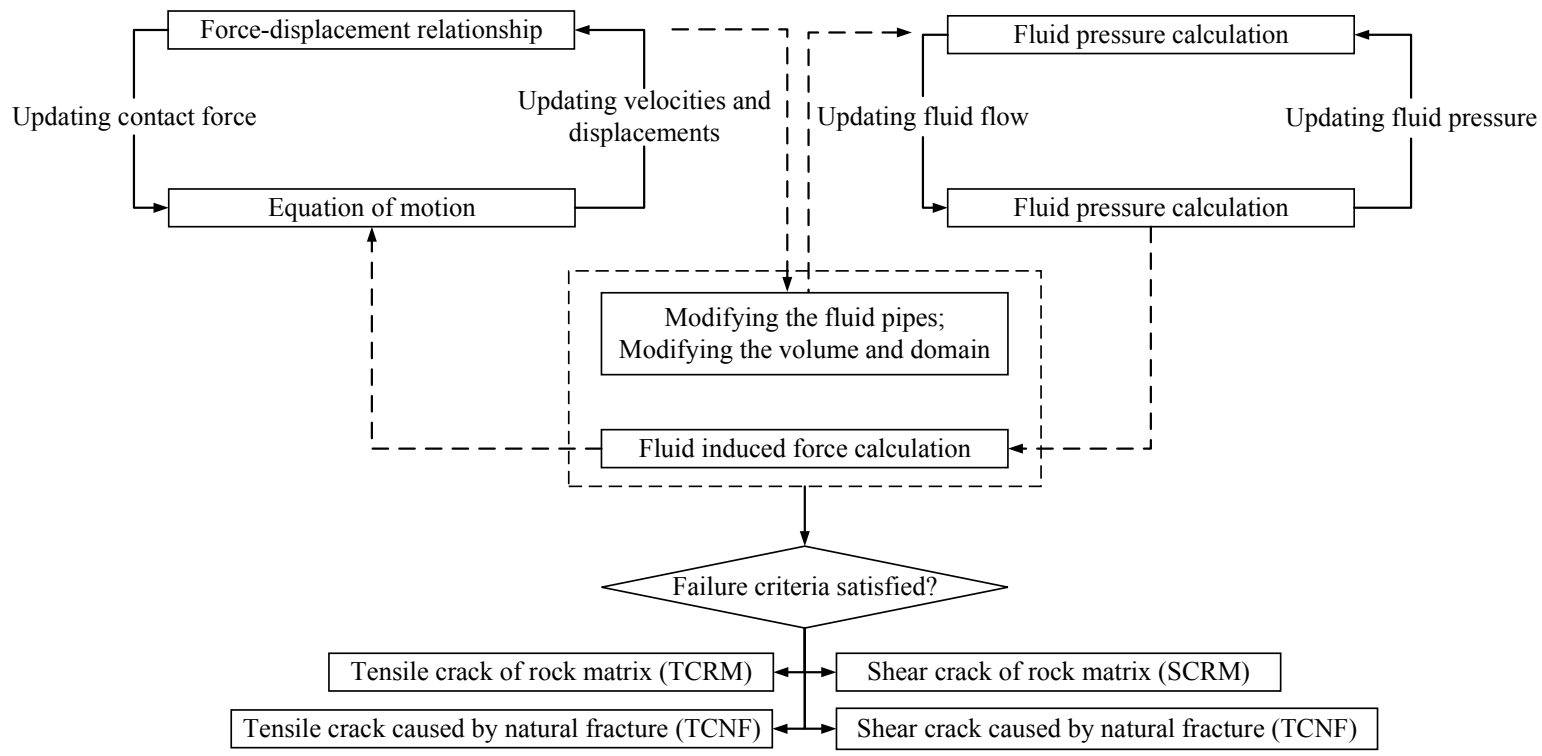

Figure 7. Modeling procedures for a hydro-mechanical coupling.

\section{Natural Fracture Structure}

In order to quantitatively analyze NF structure, a borehole televiewer was performed on 9103 track roadways that were newly excavated in Huahong coal mine, China. The observation sites are shown in Figure 8a; the roof and ribs of track roadways are shown in Figure 8b,c, respectively. Five boreholes were observed with the ZKXG30 borehole images instrument (Figure 8d) on site, with which three boreholes $(\Phi 28 \times 10,000 \mathrm{~mm})$ are on the roof and the other two $(\Phi 28 \times 5000 \mathrm{~mm})$ on the ribs. From the observation, abundant NFs were found in borehole images (Figure 9). 

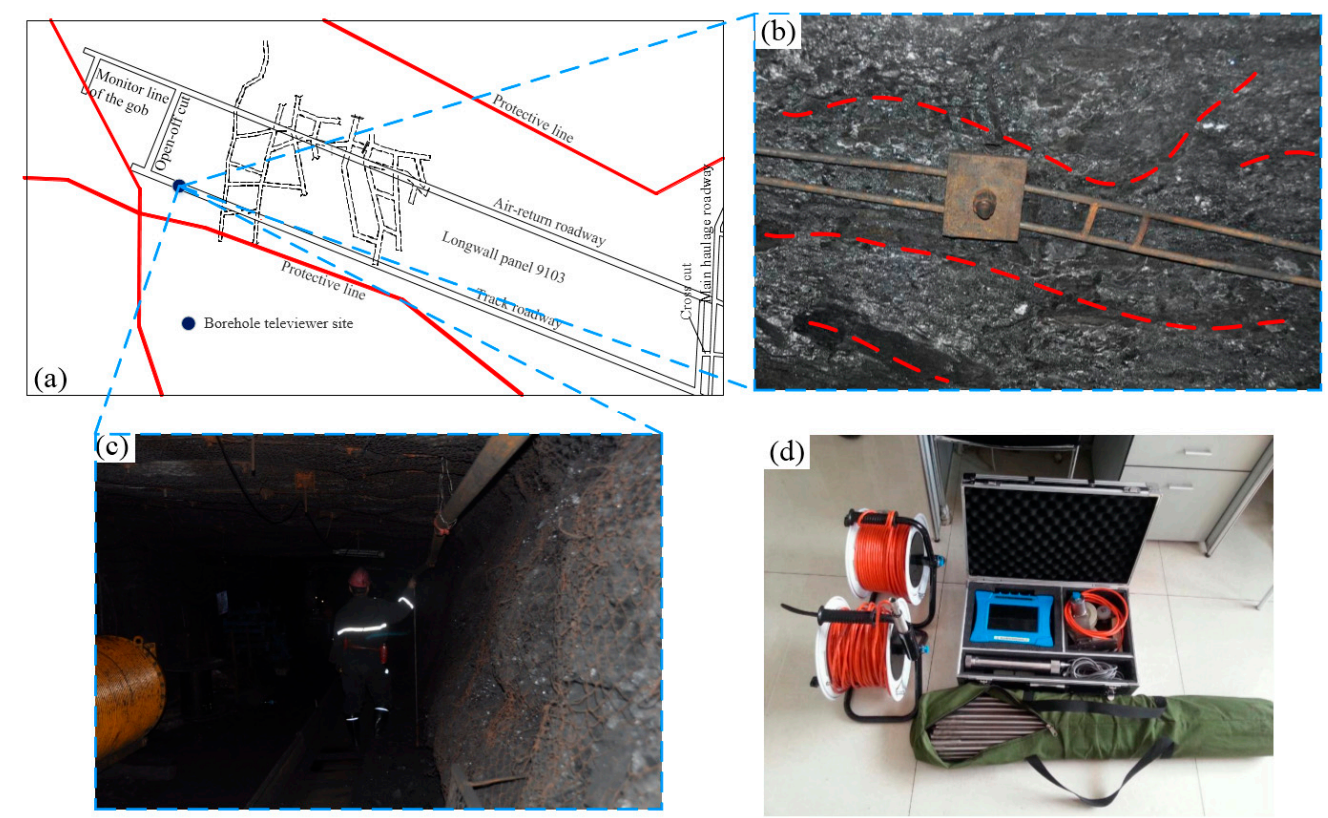

Figure 8. (a) Plan view of the study site at Huahong coal mine, China; photographs of (b) roof (c) rib; (d) test equipment of borehole image.

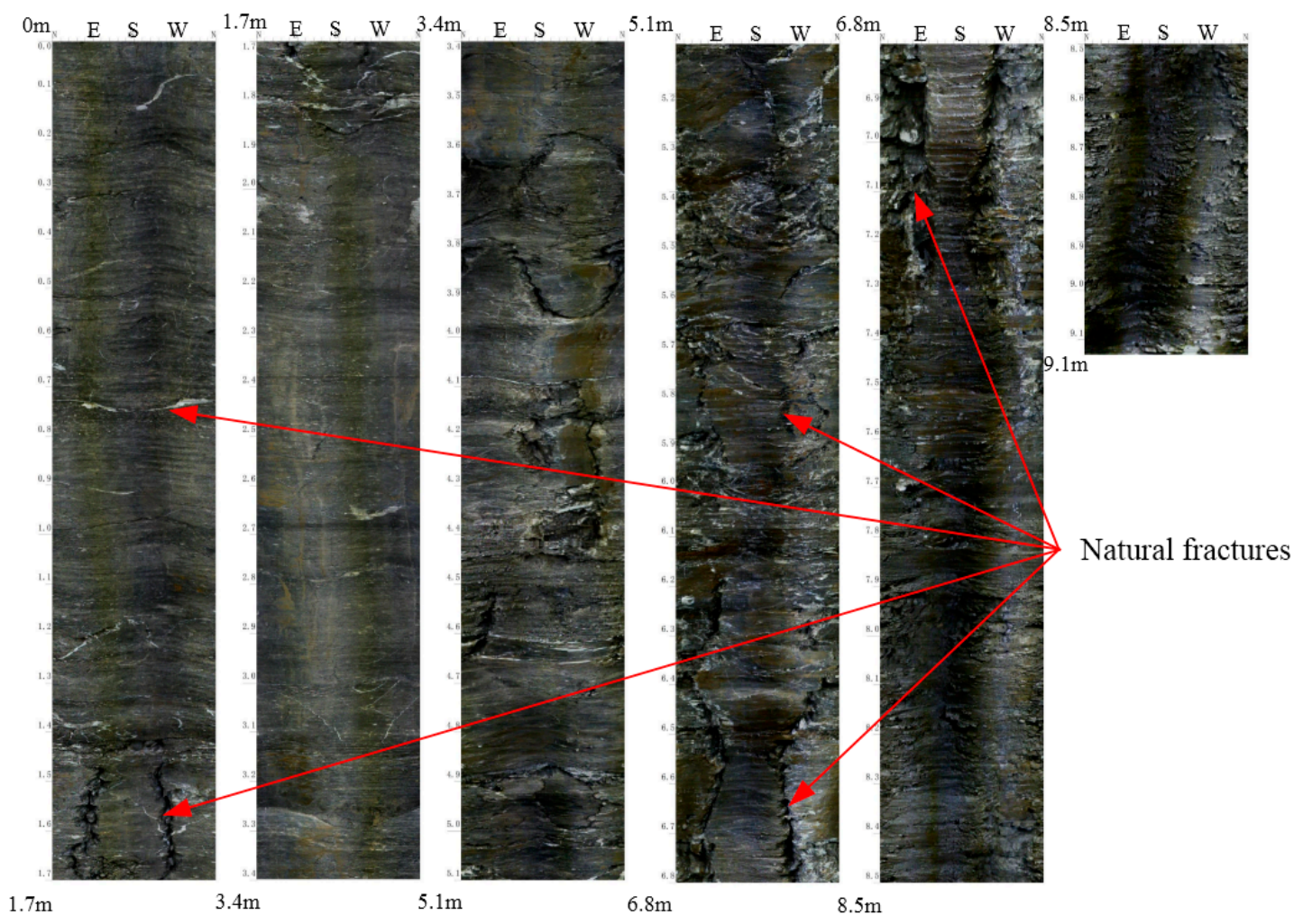

Figure 9. Optical televiewer image of the borehole drilled vertically in the roof at the Huahong coal mine, China.

Natural fracture plane (NFP) in a small area can be regarded as a two-dimension plane. An intersection line is formed while drilling the borehole on the plane. By unfolding the borehole wall, the intersection line presents three geometrical shapes. The vertical intersection between borehole and NFP forms one horizontal intersection line (Figure 10a), parallel intersection forms two vertical 
intersection lines (Figure 10b) and inclined intersection forms one standard sine curve (Figure 10c). The dip angle of NFP $\alpha$ can be calculated by the following equation:

$$
\tan \angle \alpha=\frac{h_{a b}}{2 r}=\frac{x_{B}-x_{A}}{2 r}
$$

where $h_{a b}$ is the height difference of Points $A$ and $B$ in Figure 10c; $r$ is the radius of the borehole; $x_{A}$ and $x_{B}$ are the x-coordinate of Points $A$ and $B$, respectively.
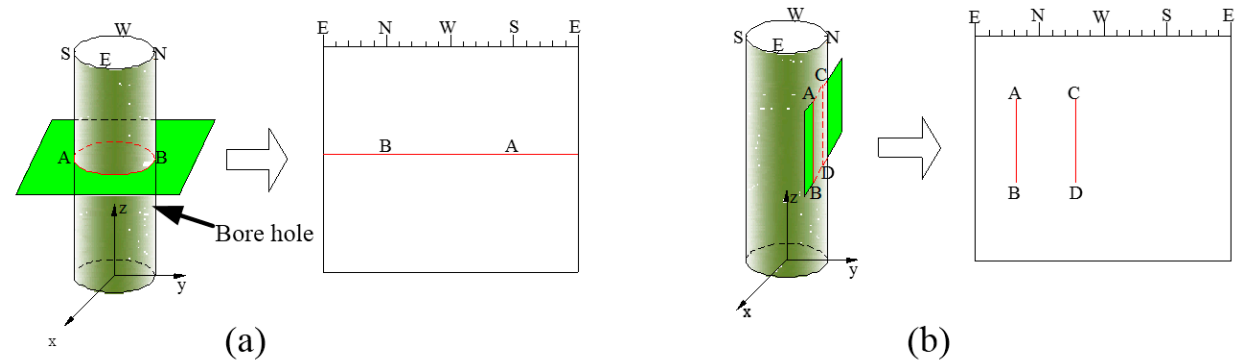

(b)

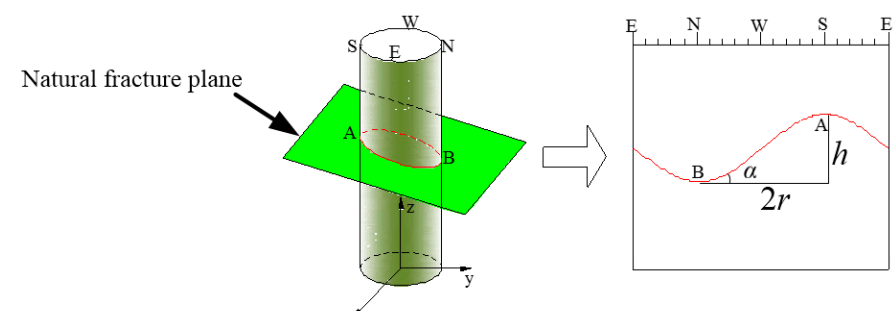

(c)

Figure 10. The intersection of the drill hole and the structure surface: (a) vertical intersection; (b) parallel intersection and (c) inclined intersection.

Although the theoretical quantitative analysis is conducted on the structure of NFP obtained from borehole images in Figure 10, the uncertainties in the borehole imaging process make the analysis much more complicated in real situations. The impact of gravel stripping and collapse within borehole imaging is inevitable. However, considering NF density-the main factor considered in this paper is determined on the basis of the statistics of abundant NFs-minor errors have little impact on the statistical results of NFs [40].

In this paper, NF density was determined by borehole images of accumulative length of $40 \mathrm{~m}$. One-thousand-and-seventy-four NFs, in total, were observed, and the geometrical parameters of each fracture were calculated, including length, aperture, and dip angle. Figure 11 shows the borehole images, three-dimensional virtual maps, and statistical results of natural fractures which were obtained from a borehole on the right side of the roof plate.

According to statistical results (Figure 12), the frequency is over 240 (the highest) from $180 \mathrm{~mm}$ to $200 \mathrm{~mm}$, and all lengths of NFs were normally distributed. The equation is defined as:

$$
y=24+\frac{15711}{59 \sqrt{\pi / 2}} \times e^{-2 \times\left(\frac{l-183}{59}\right)^{2}}
$$

The $R$-square of Equation (25) is 0.93. Although NF aperture also varied to a certain degree, the variance was small compared to the variance of the length. Therefore, the average of the aperture values of $1074 \mathrm{NFs}$ was selected as the parameter of the aperture parameter $(d=2.56 \mathrm{~mm})$ for the model. The dip angles of NF were found to be normally distributed in three areas. Natural fracture density $\rho$ can be defined as the sum of NF lengths $l_{\text {sum }}$ to the measured area $A_{\text {sum }}$ ratio:

$$
\rho=\frac{l_{\text {sum }}}{A_{\text {sum }}}
$$


Based on the statistical results, NF density in this paper was determined as $48 / \mathrm{m}(\rho=48 / \mathrm{m})$. The results were used to generate the NF in the proposed coupled hydro-mechanical model through an independent sub-program.

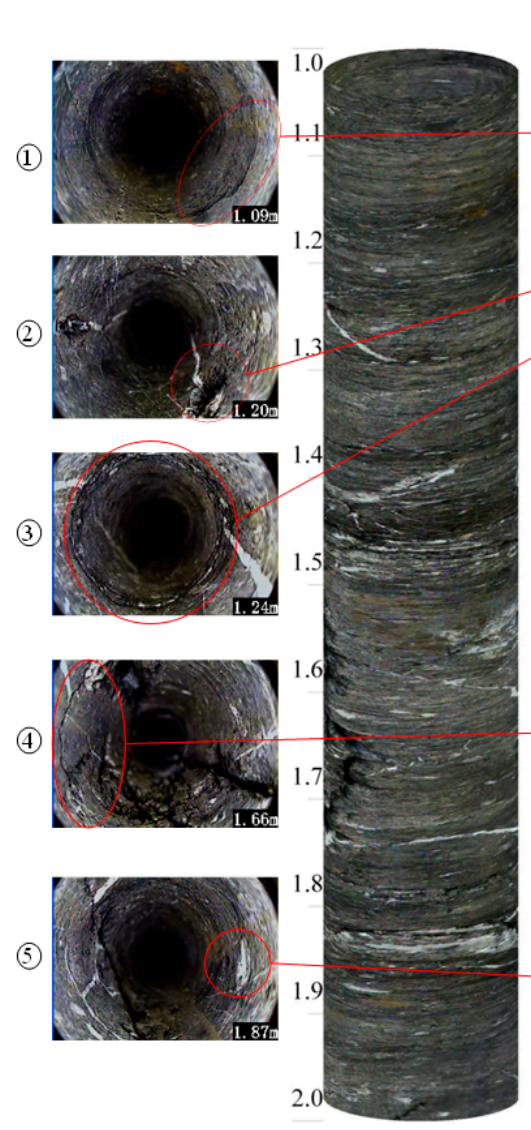

(a)

(b)

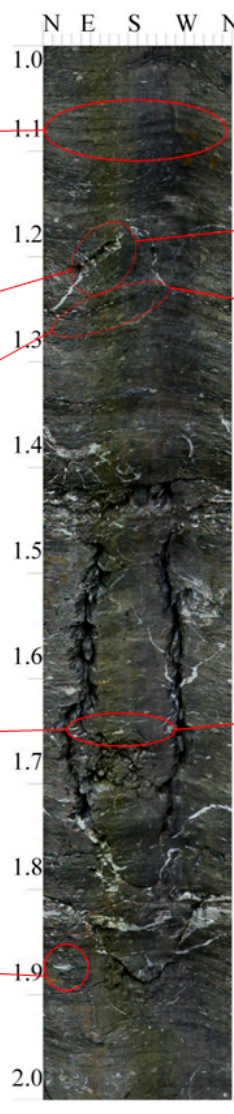

(c)

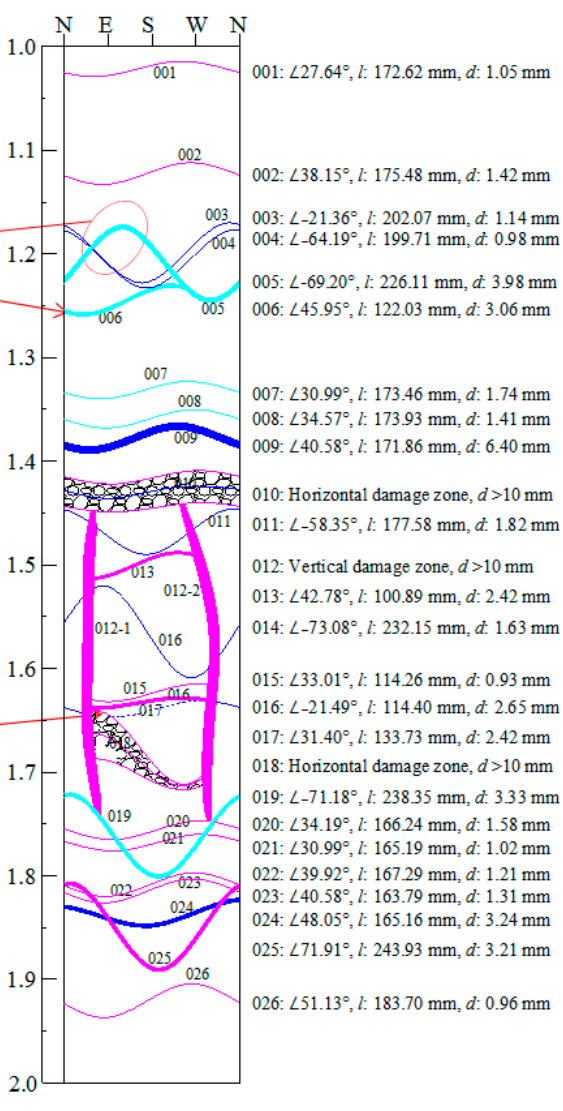

(d)

Figure 11. (a) Typical point; (b) virtual map of borehole image in 3-D; (c) plan view of the drill hole; (d) measurements of natural fracture (NF).

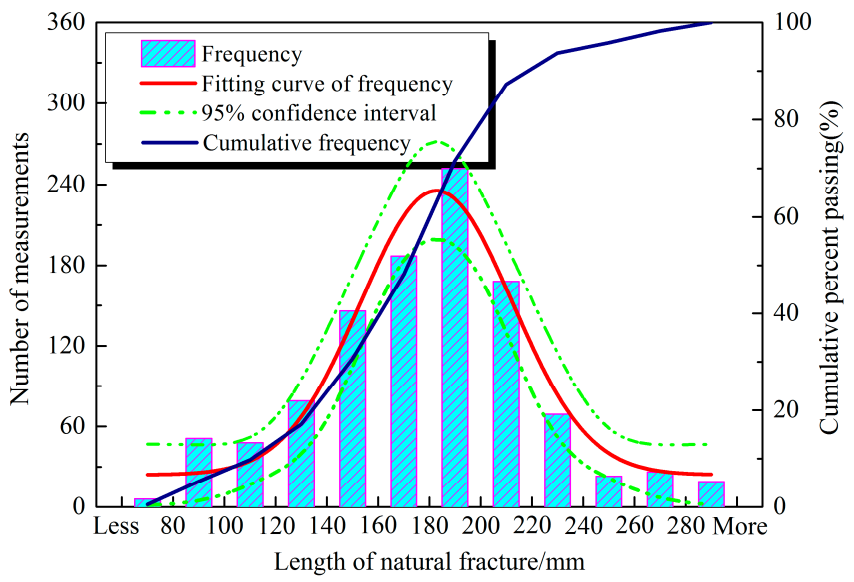

(a)

Figure 12. Cont. 


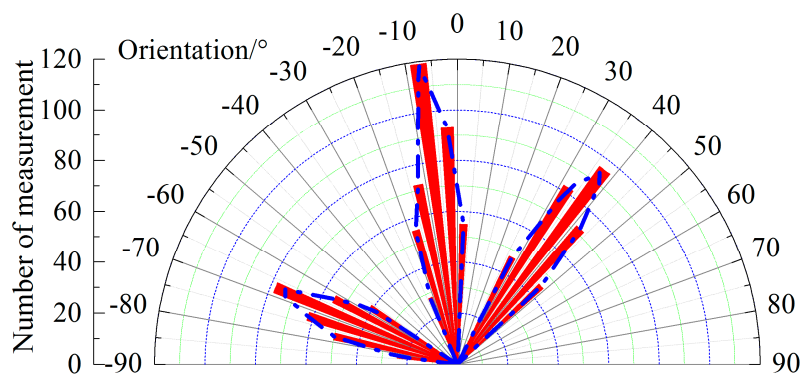

(b)

Figure 12. Statistical results of natural fracture (NF) (a) length and (b) dip angle.

\section{Model Procedure and Validation}

\subsection{Model Procedure}

In this paper, a $1.0 \mathrm{~m} \times 1.0 \mathrm{~m}$ model was built, in which natural fracture (NF) was generated according to the statistical results in Section 3. In order to research the effects of NF on HFN propagation, $\pm 25 \%$ and $\pm 50 \%$ changes were made to the statistical results of NF density during the process of generating NF using the model, which means that NF density $\rho$ was set as $24(-50 \%), 36(-25 \%)$, $48,60(+25 \%)$ and $96 / \mathrm{m}(+50 \%)$, respectively. The length and dip angles of NFs, however, followed a normal distribution based on the statistical results of geometrical structure in Section 3. The average $\mathrm{NF}$ aperture value $(d=2.56 \mathrm{~mm})$ remained the same.

The injection hole was formed through removing particles in the model center. The confining pressure in vertical orientation is represented by $S_{H}$ and horizontal orientation by $S_{h}$. The stress difference of confining pressure $\Delta h$ ranges from 0 to $18 \mathrm{MPa}$.

\subsection{Model Validation}

In the proposed model, the micro-properties of intact specimens were firstly calibrated through a trial and error method. According to the authors' previous works [41], the calibrated micro-properties are listed in Table 1. The comparison between the numerical simulation results and physical experimentation results of rock formation under different CPRs is shown in Figure 13. The figure shows that the results obtained from numerical simulation are in good agreement with those from the physical experiments.

Table 1. Micro-properties used in intact rock for simulated specimens after calibration [41].

\begin{tabular}{ccc}
\hline Micro-Parameters & Unit & Values \\
\hline The minimum particle radius $\left(R_{\min }\right)$ & $\mathrm{mm}$ & 1.0 \\
Ratio of maximum and minimum particle radius $\left(R_{\max } / R_{\min }\right)$ & - & 1.67 \\
Particle density $\left(\rho_{p}\right)$ & $\mathrm{kg} / \mathrm{m}^{3}$ & 2800 \\
Particle friction coefficient $(\mu)$ & - & 0.55 \\
Young's modulus of the particle $(E)$ & $\mathrm{GPa}$ & 14.4 \\
Parallel-bond radius multiplier $(\lambda)$ & - & 1.0 \\
Young's modulus of the parallel bond $\left(\bar{E}_{c}\right)$ & $\mathrm{GPa}$ & 14.4 \\
Normal stiffness of the parallel bond (mean) & $\mathrm{MPa}$ & 14.7 \\
Normal stiffness of the parallel bond (std deviation) & $\mathrm{MPa}$ & 3.6 \\
Shear stiffness of the parallel bond (mean) & $\mathrm{MPa}$ & 9.2 \\
Shear stiffness of the parallel bond (std deviation) & $\mathrm{MPa}$ & 2.4 \\
\hline
\end{tabular}




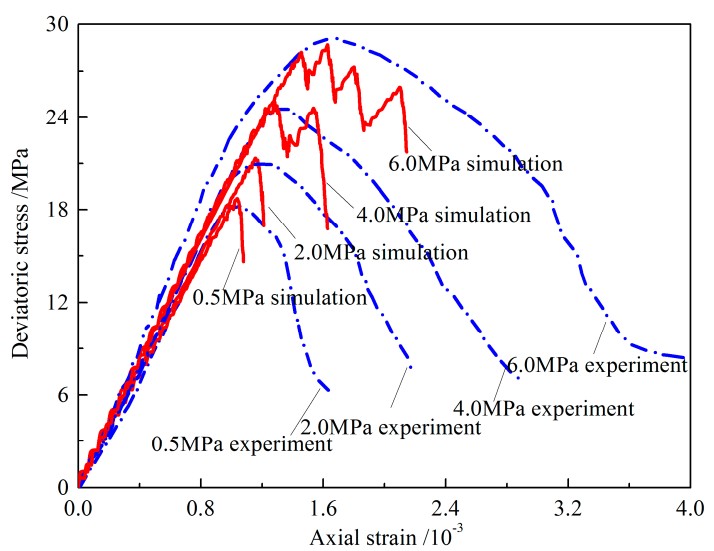

Figure 13. Comparison between experimental and numerical deviation stress versus axial strain curves.

The micro-parameters of the SJ were calibrated based on the interactive behavior between NF and HF in physical experiments. The selected intersection angles $\theta$ and $\Delta h\left(\Delta h=\left|S_{H}-S_{h}\right|\right)$, in numerical simulations, were the same to those conducted in physical experiments [42-44]. When the SJ and fluid parameters were fixed, $\theta$ and $\Delta h$ in the rock formation played a decisive role in the results of interaction between HF and NF. In this study, three typical $\theta\left(\theta=30^{\circ} ; 60^{\circ} ; 90^{\circ}\right)$ values were adopted. The SJ and fluid parameters were adjusted repeatedly with the use of the trial-and-error method, so that the results of the interactions between HFs and NFs in the numerical simulations were the same as those in the physical experiments. Figure $14 \mathrm{a}, \mathrm{b}, \mathrm{d}, \mathrm{e}, \mathrm{g}, \mathrm{h}$ demonstrates that the HF opens the NF; Figure $14 c$,f,i demonstrates that the HF crosses the NF.

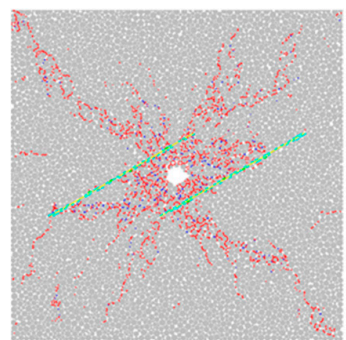

(a) $\theta=30^{\circ}, \Delta h=12 \mathrm{MPa}$

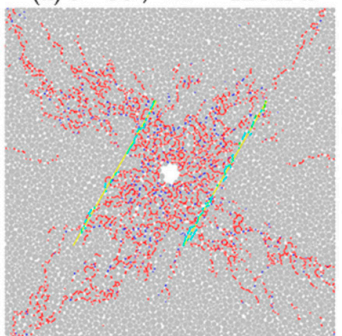

(d) $\theta=60^{\circ}, \Delta h=3.5 \mathrm{MPa}$

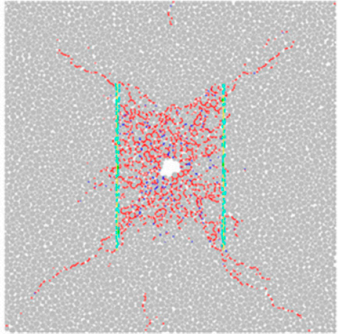

(g) $\theta=90^{\circ}, \Delta h=1 \mathrm{MPa}$

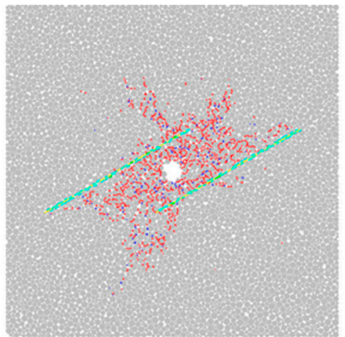

(b) $\theta=30^{\circ}, \Delta h=14 \mathrm{MPa}$

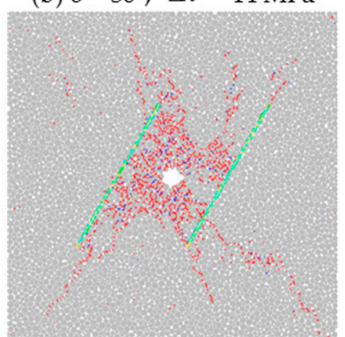

(e) $\theta=60^{\circ}, \Delta h=6.9 \mathrm{MPa}$

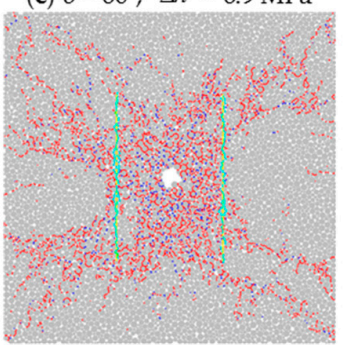

(h) $\theta=90^{\circ}, \Delta h=3.4 \mathrm{MPa}$

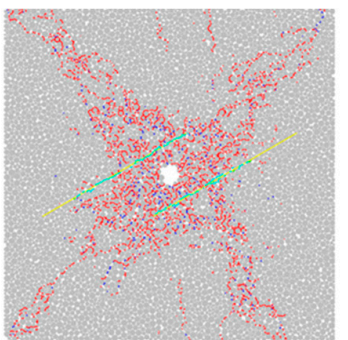

(c) $\theta=30^{\circ}, \Delta h=16 \mathrm{MPa}$

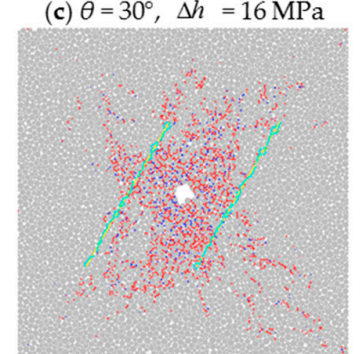

(f) $\theta=60^{\circ}, \Delta h=10 \mathrm{MPa}$

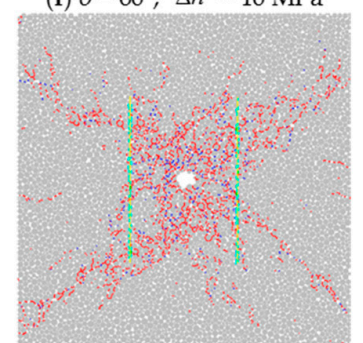

(i) $\theta=90^{\circ}, \Delta h=9 \mathrm{MPa}$

Figure 14. Numerical results of HF and NF interactions at different values of $\theta$ and $\Delta h$. 
The physical experiments and numerical simulation suggested that:

(1) The possibility of HFs crossing NFs increases as $\theta$ increases. This is due to the increasing difficulty for fluid to flow into NFs when they are oriented closer to the normal value of the HF propagation path.

(2) The possibility of HFs crossing NFs increases along with the increase of $\Delta h$. When there is a greater pressure difference between the horizontal orientation and vertical orientation, it is easier for HF propagation along the maximum principal stress.

The separate line curve presented a negative exponent change. The calibrated scenarios appeared similar to the experimental findings of [42-44], as shown in Figure 15. The SJ parameters after calibration and fluid parameters of numerical simulation are listed in Tables 2 and 3.

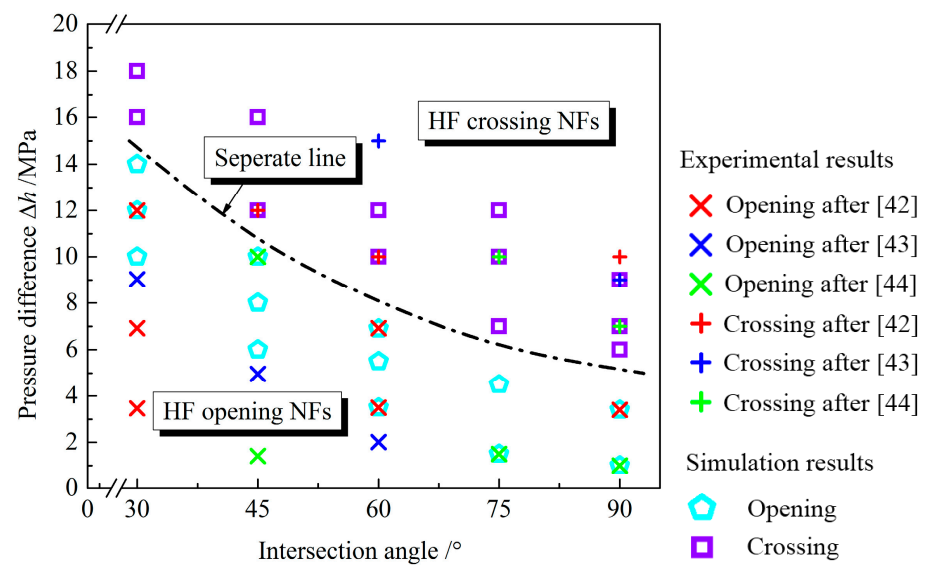

Figure 15. Comparison between the interactive behavior in the physical experiment and numerical simulation.

Table 2. Micro-properties used in smooth joint (SJ) contact for simulated specimens after calibration.

\begin{tabular}{cccc}
\hline \multicolumn{2}{c}{ Parameters } & Unit & Values \\
\hline & Normal stiffness $\left(\bar{k}_{n j}\right)$ & $\mathrm{GPa} / \mathrm{m}$ & 20.5 \\
& Shear stiffness $\left(\bar{k}_{n j}\right)$ & $\mathrm{GPa} / \mathrm{m}$ & 18.5 \\
Smooth joint model & $\mathrm{MPa}$ & 1.5 \\
& Tensile strength & $\mathrm{MPa}$ & 1.5 \\
& Cohesion & $\circ$ & 0 \\
\hline
\end{tabular}

Table 3. Computational parameters of fluid properties.

\begin{tabular}{ccc}
\hline Fluid Parameters & Unit & Values \\
\hline Injection rate & $\mathrm{m}^{3} \cdot \mathrm{s}^{-1}$ & $2.0 \times 10^{-6}$ \\
Fluid bulk modulus $\left(K_{f}\right)$ & $\mathrm{GPa}$ & 2.0 \\
Fluid dynamic viscosity $(\mu)$ & $\mathrm{Pa} \cdot \mathrm{s}$ & $1.1 \times 10^{-4}$ \\
Initial fluid aperture $\left(a_{z e o}\right)$ & $\mathrm{m}$ & $2.7 \times 10^{-5}$ \\
Infinite fluid aperture $\left(a_{\text {inf }}\right)$ & $\mathrm{m}$ & $2.7 \times 10^{-6}$ \\
\hline
\end{tabular}

In addition to the initiation, propagation, and coalescence of HFN, breakdown pressure was also taken into consideration in simulations of hydraulic fracture with the proposed model. A typical regression equation was proposed to calculate the breakdown pressure. Wang et al. [45] analyzed the effect of tensile strength and initial stress parameters on breakdown pressure. They discussed the coefficients of the equation, based on fitting curves, and suggested that both anisotropy and inhomogeneity of rocks would result in different equation coefficients. In addition, Fjar et al. [46] 
put forward another regression equation in which the Poisson's ratio $v$ of the crack was taken into consideration to calculate breakdown pressure $P_{b}$ :

$$
P_{b}=\frac{\sigma_{t}+S_{H}+3 S_{h}+P_{0}-\omega(1-2 v) /(1-v)}{2-\omega(1-2 v) /(1-v)}
$$

where $\omega$ is the poroelastic coefficient; $\sigma_{t}$ is the rock tensile strength.

In order to verify the applicability of the proposed model, the simulated breakdown pressure value was compared with the calculated value through Equation (27) under same confining ratio in this study. The tensile strength of the NF density model built in Section 3 was $2.48 \mathrm{MPa}(\rho=48 / \mathrm{m}), v$ was 0.22 , and $\omega$ ranged from 0.15 to 0.24 [47]. The initial pore pressure was set as $0\left(P_{0}=0\right)$, the confining pressure on the $y$ axis $\left(S_{H}\right)$ was set as $15 \mathrm{MPa}$, and on the $x$-axis $\left(S_{h}\right)$ varied from 10 to $15 \mathrm{MPa}$. The parameters of rock and fluid were adopted from Tables 1-3. Figure 16 demonstrates the comparison between the result obtained from theoretical equation and that from numerical simulations under different CPRs. The errors between the two were within 15\%, meaning that the proposed model is applicable to hydraulic fracture simulation.

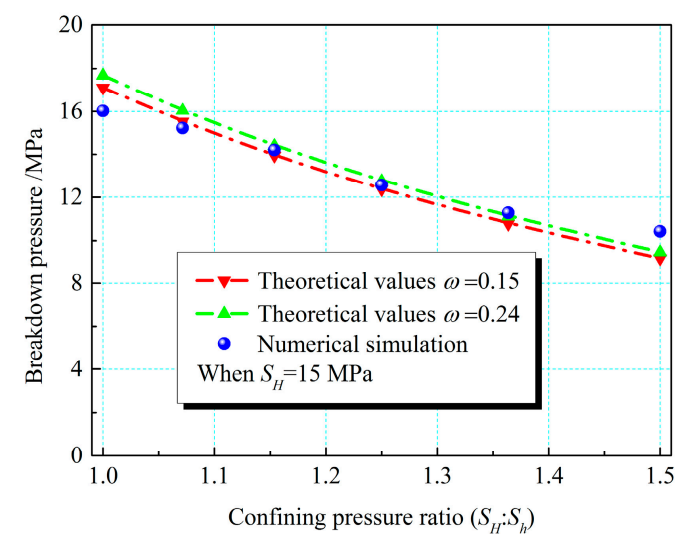

Figure 16. Comparison of breakdown pressure under different confining pressure ratios obtained by the theoretical equation and numerical simulations.

\section{Results and Analysis}

In addition to NF density, some other external factors also influence the initiation, propagation, and coalescence of HFN:CPR and injection rate. Based on the calibrated micro-parameters in Section 4, a series of numerical simulations were performed to research the influence of NF density on the evolution of HFN propagation. Meanwhile, the influence of CPR and injection rate were also taken into consideration.

\subsection{Evolution Process}

Stimulated reservoir volume (SRV) is widely used to describe the efficiency of rock reservoir fracturing, which is defined as [48]:

$$
S R V=L_{x} \times L_{y} \times H_{z}
$$

where $L_{x}$ and $L_{y}$ are the width and the length of SRV, respectively; the thickness of the numerical model $H_{z}$ is assumed to be that of the unit length.

Figure 17 demonstrates the evolution of SRV under different NF densities, showing that a constant declining of SRV increases rate. Under different NF density conditions, the increase of time step ( $>2000)$ would lead to bigger variances in SRV. The higher the NF density, the bigger the SRV. Particularly, SRV under maximum NF density $(\rho=72 / \mathrm{m})$ was $31.54 \%$ larger than that of the minimum NF density $(\rho=24 / \mathrm{m})$. 


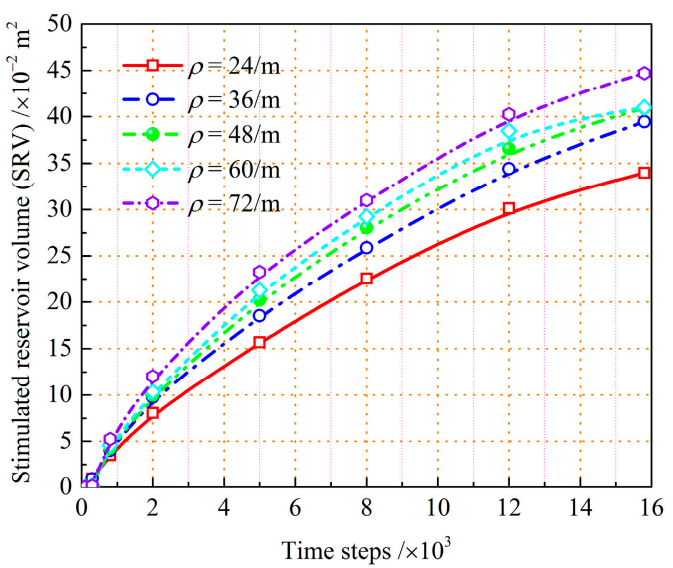

Figure 17. Change of stimulated reservoir volume (SRV) with time steps when natural fracture (NF) density ranges from 24 to $72 / \mathrm{m}$ when injection rate is $2.0 \times 10^{-6} \mathrm{~m}^{3} / \mathrm{s}$ and $S_{H}: S_{h}=10: 5$.

Figure 18 demonstrates the evolution of injection pressure under different NF densities. Within 800 time steps, the concentration area of injection pressure (CAIP) remained similar under different NF densities, because rock itself had resistance capacity to deformation in this stage. With the increase of time steps, however, the gradient of injection pressure and CAIP gradually differentiated from their prior values, because the strength of the rock with high NF density was low, and even low injection pressure could fracture the rock formations. The higher the NF density, the smaller of the injection pressure gradient, and the bigger the CAIP. In addition, high NF density made the propagation and coalescence of cracks easier in rock formations, which resulted in a larger CAIP.

Step 200

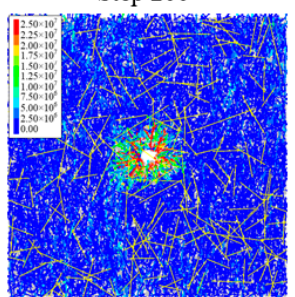

$\rho=24 / \mathrm{m}$

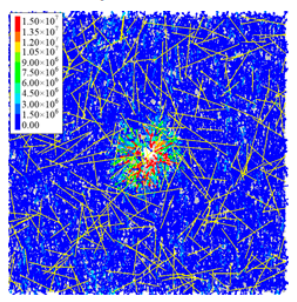

$\rho=36 / \mathrm{m}$

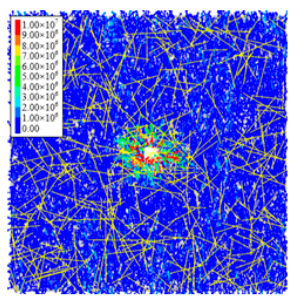

$\rho=48 / \mathrm{m}$
Step 800

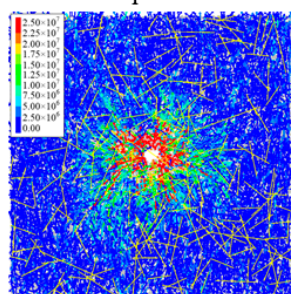

$\rho=24 / \mathrm{m}$

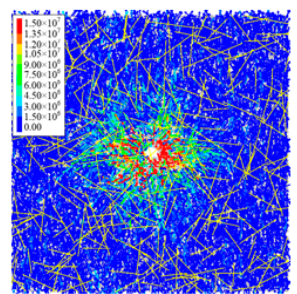

$\rho=36 / \mathrm{m}$

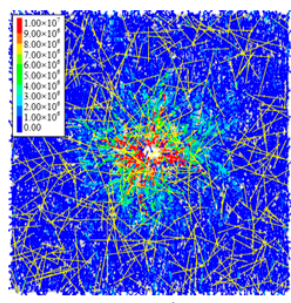

$\rho=48 / \mathrm{m}$
Step 8000

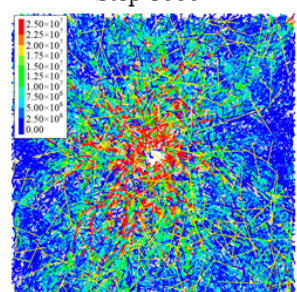

$\rho=24 / \mathrm{m}$

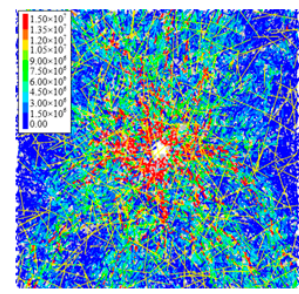

$\rho=36 / \mathrm{m}$

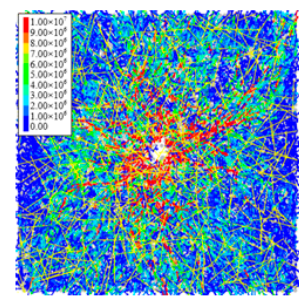

$\rho=48 / \mathrm{m}$
Step 16000

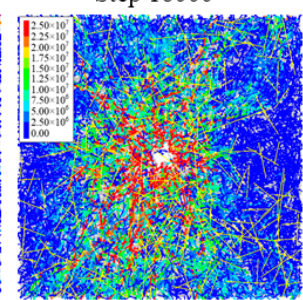

$\rho=24 / \mathrm{m}$

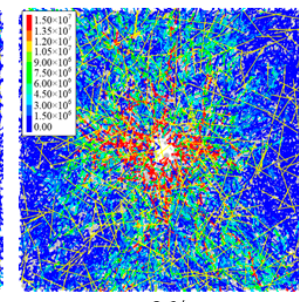

$\rho=36 / \mathrm{m}$

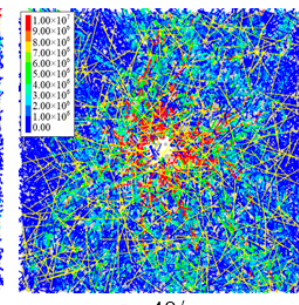

$\rho=48 / \mathrm{m}$

Figure 18. Cont. 


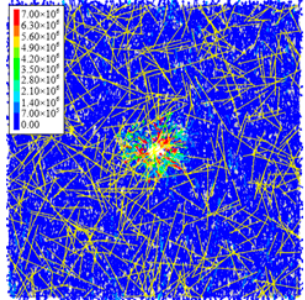
$\rho=60 / \mathrm{m}$

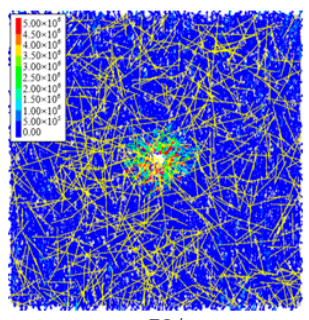

$\rho=72 / \mathrm{m}$

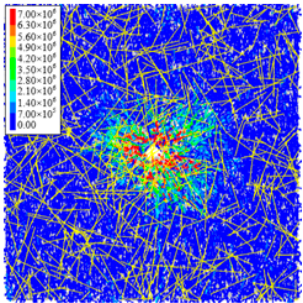
$\rho=60 / \mathrm{m}$

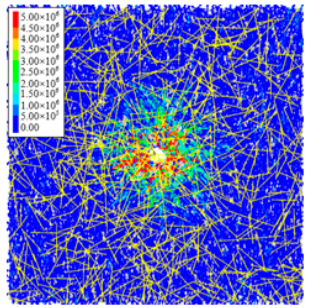

$\rho=72 / \mathrm{m}$

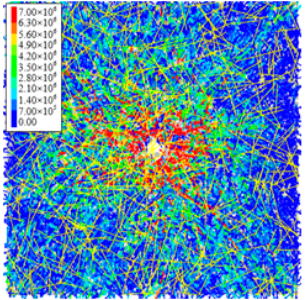
$\rho=60 / \mathrm{m}$

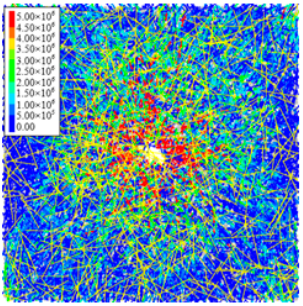

$\rho=72 / \mathrm{m}$

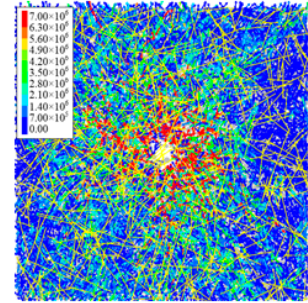

$\rho=60 / \mathrm{m}$

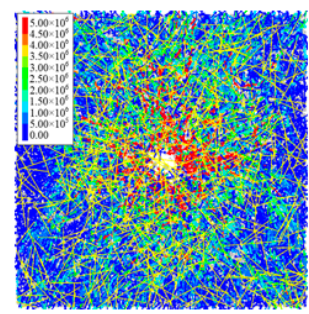

$\rho=72 / \mathrm{m}$

Figure 18. Evolution process of injection pressure induced by NF densities of rock formations when injection rate is $2.0 \times 10^{-6} \mathrm{~m}^{3} / \mathrm{s}$ and $S_{H}: S_{h}=10: 5$.

Figure 19 shows the changes of different crack types under five NF densities. The fitting curve equations reflecting the relationship between the number of cracks and NF density are listed in Table 4 . When NF density was relatively low $(\rho=24 / \mathrm{m})$, TCRM had the highest value under all confining ratios. The medium NF density $(\rho=36 / \mathrm{m}$ or $48 / \mathrm{m})$ would lead to the increase of TCNF and SCNF values, and SCNF value presented an exponential increase in trend. In this process, TCRM and SCNF were close to each other in value. The value of SCNF, however, would exceed that of TCRM and become dominant when NF density was high $(\rho=60 / \mathrm{m}$ or $72 / \mathrm{m})$. Additionally, NF density had limited influence on the value of SCRM, which always remained minimal compared to other crack types.

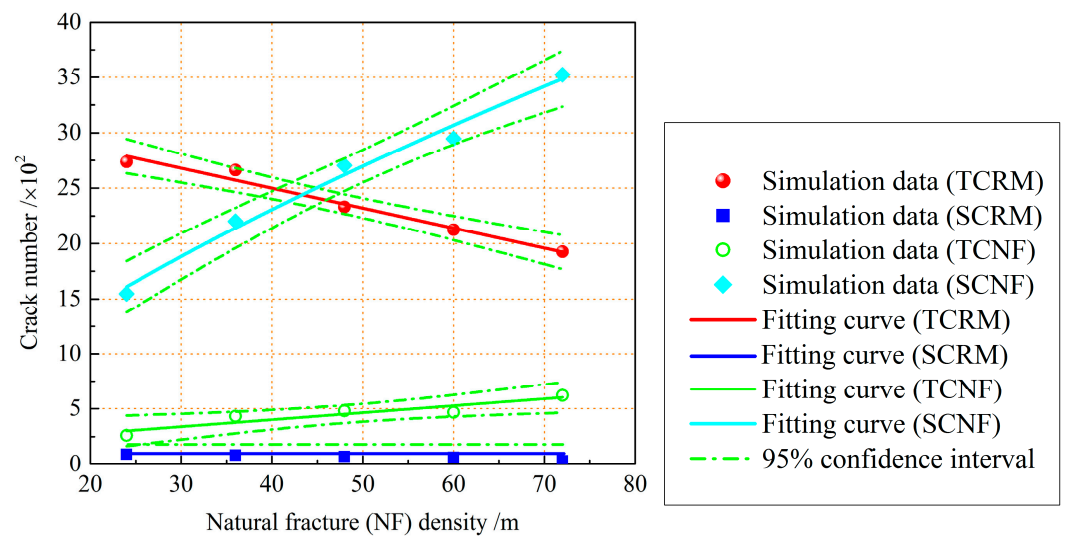

Figure 19. Variation of tensile crack of rock matrix (TCRM), shear crack of rock matrix (SCRM), tensile crack of natural fracture (TCNF), and shear crack of rock matrix (SCNF) in various NF densities.

Table 4. Fitting curve equations of the number of cracks for different NF densities.

\begin{tabular}{ccc}
\hline Confining Pressure Ratios & Fitting Curve Equations & $\boldsymbol{R}$-Squared \\
\hline Tensile crack of rock matrix (TCRM) & $y=-0.18 x+32.2$ & 0.96 \\
Shear crack of rock matrix (SCRM) & $y=0.67$ & 0.98 \\
Tensile crack caused by natural fracture (TCNF) & $y=0.06 x+1.5$ & 0.81 \\
Shear crack caused by natural fracture (SCNF) & $y=0.36 x^{0.05}$ & 0.92 \\
\hline
\end{tabular}




\subsection{Considering Confining Pressure}

In this section, the influence of NF density on HFN propagation under different CPRs, $S_{H}: S_{h}=10: 15,10: 10$, and 10:5 were investigated respectively, and all parameters required were adopted from Tables 1-3. Figure 20 demonstrates the influence of NF density on injection pressure under different CPRs. When $S_{H}: S_{h}=10: 15$, the injection pressure in the rock with the NF density of $24 / \mathrm{m}$ approached the maximum value $(60 \mathrm{MPa})$, because both rock strength and confining pressure reached their maximum levels. All CAIPs of rock formations with different densities were mainly developed horizontally. As to $S_{H}: S_{h}=10: 10$ or 10:5, the injection pressure decreased sharply. When horizontal confining pressure and vertical confining pressure were same $\left(S_{H}: S_{h}=10: 10\right)$, however, CAIP expanded gradually and distributed evenly on horizontal and vertical orientations. When confining pressure on vertical orientation was larger than that on horizontal orientation $\left(S_{H}: S_{h}=10: 5\right)$, CAIP mainly developed along vertical orientation. Under the same CPR, although CAIP remained almost constant, the gradient of maximum injection pressure decreased gradually with the increase of NF density. Particularly, injection pressure presented the greatest decline during the process of NF density-increasing from $\rho=24 / \mathrm{m}$ to $48 / \mathrm{m}$.

The fitting strength envelope curves reflected the influence of NF density on breakdown pressure under different CPRs, and their corresponding equations are demonstrated in Figure 21 and Table 5, respectively. When NF density and vertical confining pressure remained constant, the increase of horizontal confining pressure would result in the growth of breakdown pressure. The maximum breakdown pressure approached $40 \mathrm{MPa}$ when the horizontal confining pressure reached $15 \mathrm{MPa}$. The increase of NF density would narrow the variances in breakdown pressures. Under the same CPR, the breakdown pressure presented negative exponential distribution with an increase of NF density, which meant that there was little variance when NF density was high.

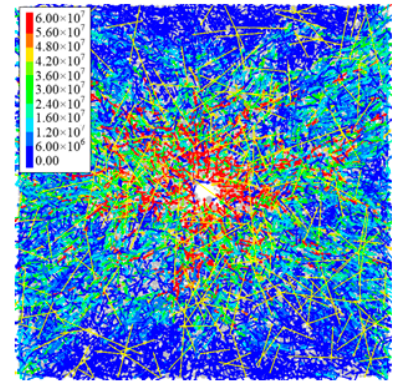

$S_{H}: S_{h}=10: 15(\rho=24 / \mathrm{m})$

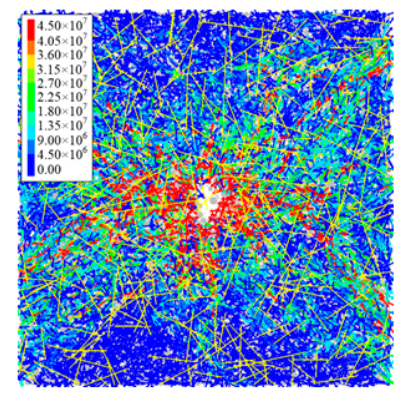

$S_{H}: S_{h}=10: 15(\rho=36 / \mathrm{m})$

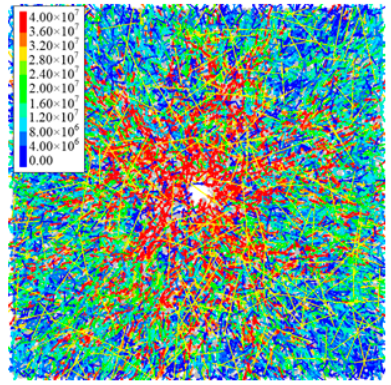

$S_{H}: S_{h}=10: 10(\rho=24 / \mathrm{m})$

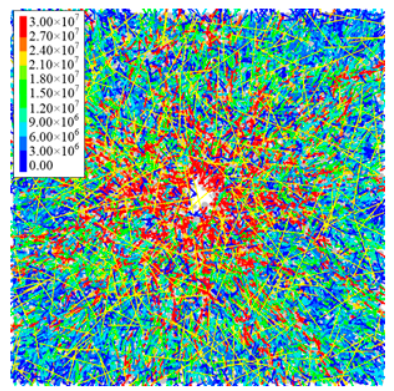

$S_{H}: S_{h}=10: 10(\rho=36 / \mathrm{m})$

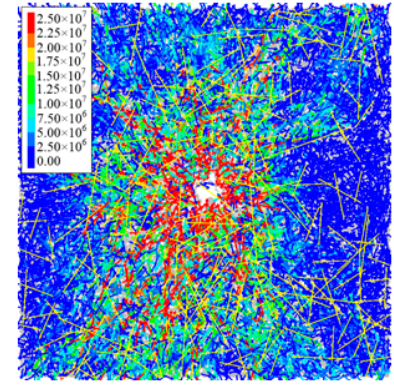

$S_{H}: S_{h}=10: 5(\rho=24 / \mathrm{m})$

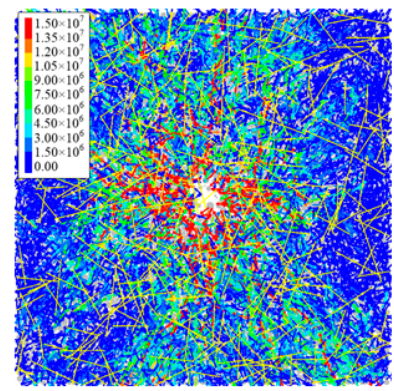

$S_{H}: S_{h}=10: 5(\rho=36 / \mathrm{m})$

Figure 20. Cont. 


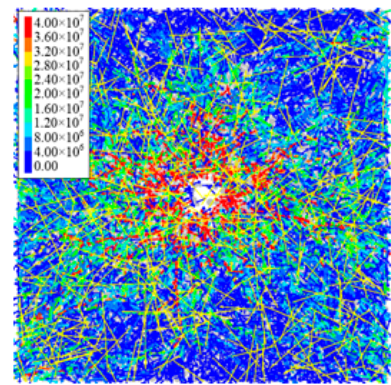

$S_{H}: S_{h}=10: 15(\rho=48 / \mathrm{m})$

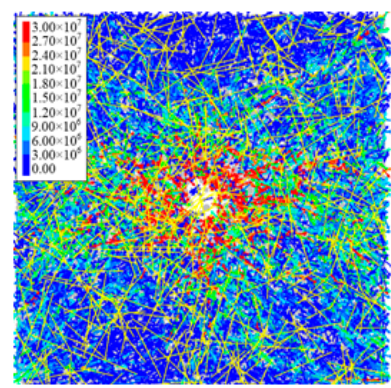

$S_{H}: S_{h}=10: 15(\rho=60 / \mathrm{m})$

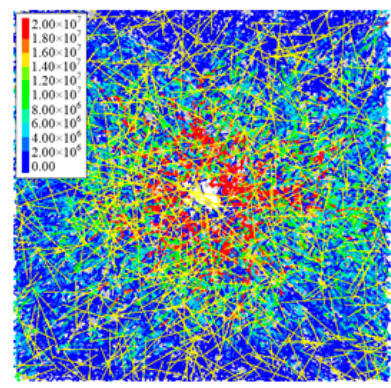

$S_{H}: S_{h}=10: 15(\rho=72 / \mathrm{m})$

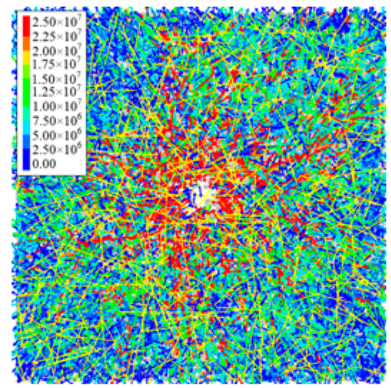

$S_{H}: S_{h}=10: 10(\rho=48 / \mathrm{m})$

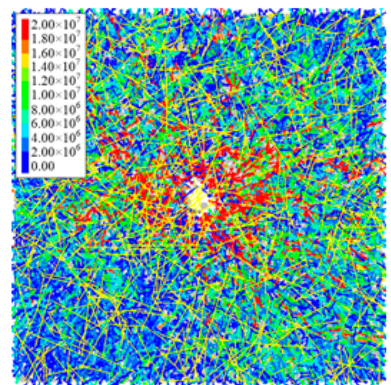

$S_{H}: S_{h}=10: 10(\rho=60 / \mathrm{m})$

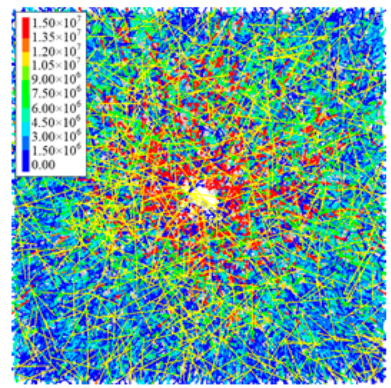

$S_{H}: S_{h}=10: 10(\rho=72 / \mathrm{m})$

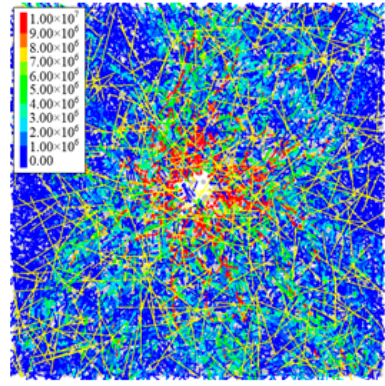

$S_{H}: S_{h}=10: 5(\rho=48 / \mathrm{m})$

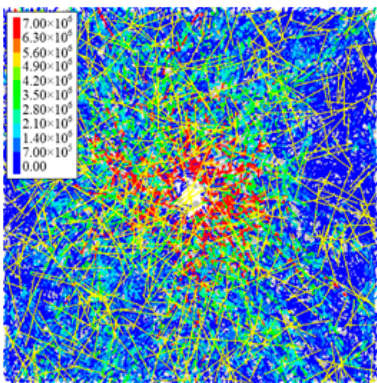

$S_{H}: S_{h}=10: 5(\rho=60 / \mathrm{m})$

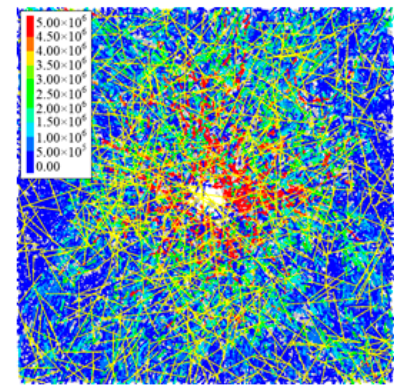

$S_{H}: S_{h}=10: 5(\rho=72 / \mathrm{m})$

Figure 20. Change of injection pressure with CPR when NF density ranges from $24 / \mathrm{m}$ to $72 / \mathrm{m}$ and injection rate is $2.0 \times 10^{-6} \mathrm{~m}^{3} / \mathrm{s}$.

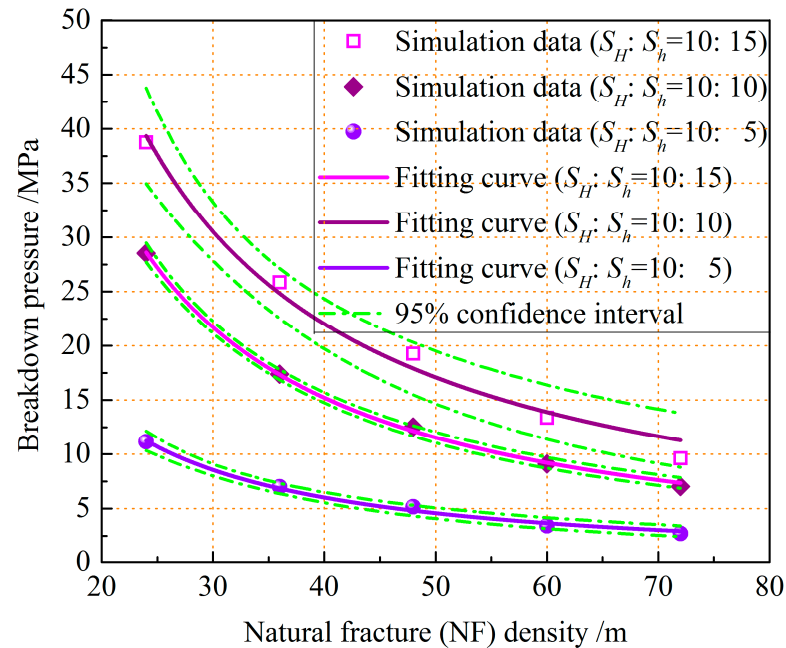

Figure 21. Variation of breakdown pressure with NF density under different confining pressure ratios and injection rate is $2.0 \times 10^{-6} \mathrm{~m}^{3} / \mathrm{s}$. 
Table 5. Fitting curve equations of beakdown pressure under different confining pressure ratios.

\begin{tabular}{ccc}
\hline Confining Pressure Ratios & Fitting Curve Equations & R-Squared \\
\hline$S_{H}: S_{h}=10: 15$ & $y=1460 x^{-1.14}$ & 0.98 \\
$S_{H}: S_{h}=10: 10$ & $y=1455 x^{-1.24}$ & 0.99 \\
$S_{H}: S_{h}=10: 5$ & $y=548 x^{-1.22}$ & 0.99 \\
\hline
\end{tabular}

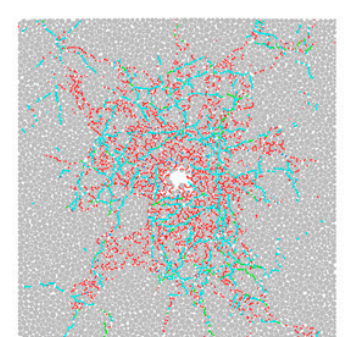

$S_{H}: S_{h}=10: 15(\rho=24 / \mathrm{m})$

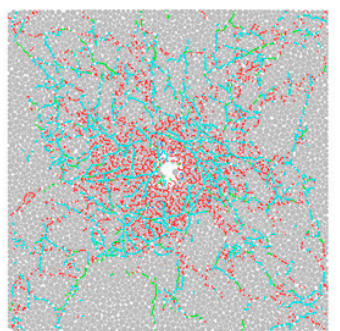

$S_{H}: S_{h}=10: 15(\rho=36 / \mathrm{m})$

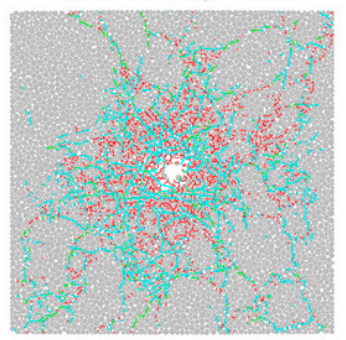

$S_{H}: S_{h}=10: 15(\rho=48 / \mathrm{m})$

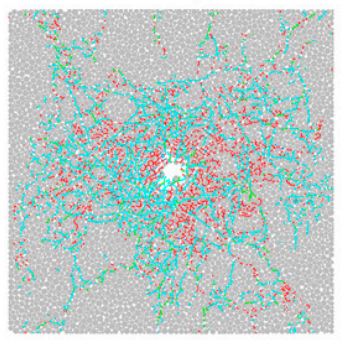

$S_{H}: S_{h}=10: 15(\rho=60 / \mathrm{m})$

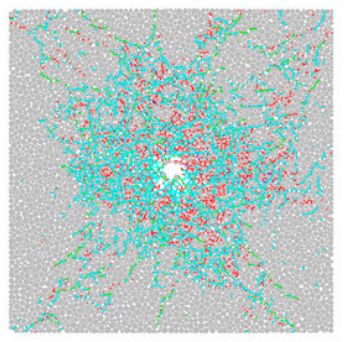

$S_{H}: S_{h}=10: 15(\rho=72 / \mathrm{m})$

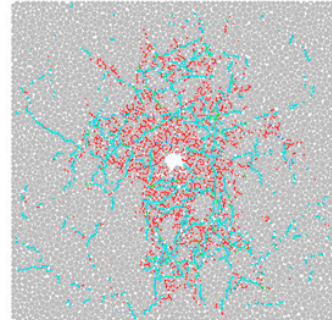

$S_{H}: S_{h}=10: 10(\rho=24 / \mathrm{m})$

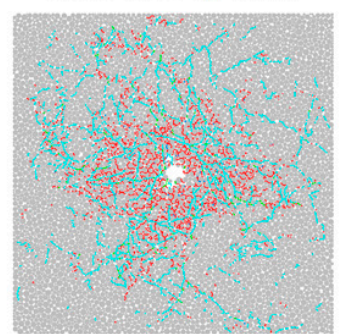

$S_{H}: S_{h}=10: 10(\rho=36 / \mathrm{m})$

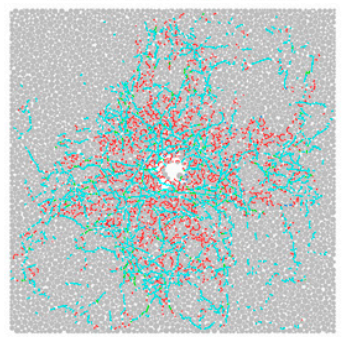

$S_{H}: S_{h}=10: 10(\rho=48 / \mathrm{m})$

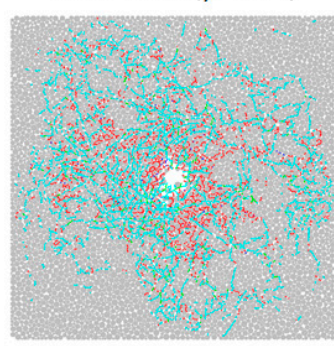

$S_{H}: S_{h}=10: 10(\rho=60 / \mathrm{m})$

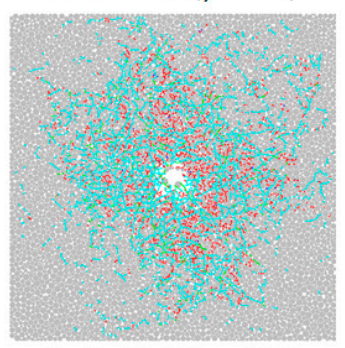

$S_{H}: S_{h}=10: 10(\rho=72 / \mathrm{m})$

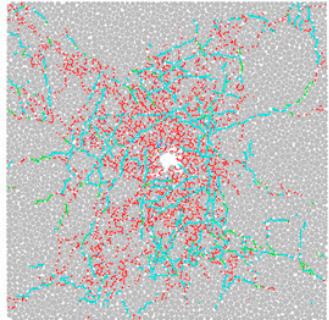

$S_{H}: S_{h}=10: 5(\rho=24 / \mathrm{m})$

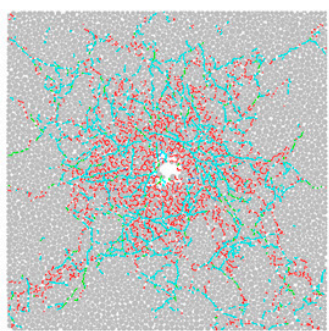

$S_{H}: S_{h}=10: 5(\rho=36 / \mathrm{m})$

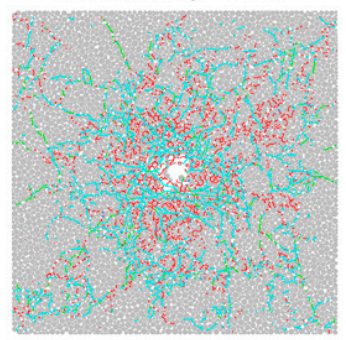

$S_{H}: S_{h}=10: 5(\rho=48 / \mathrm{m})$

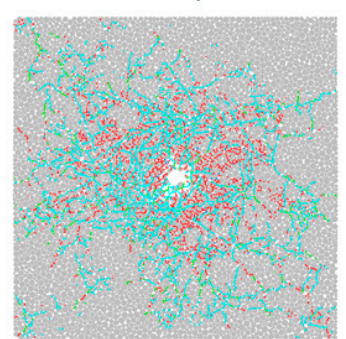

$S_{H}: S_{h}=10: 5(\rho=60 / \mathrm{m})$

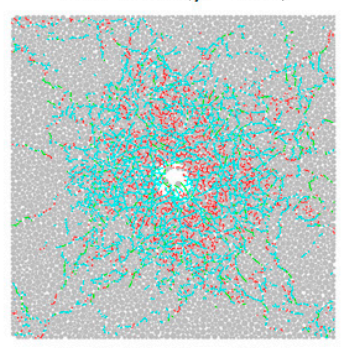

$S_{H}: S_{h}=10: 5(\rho=72 / \mathrm{m})$

Figure 22. Change of crack distribution with confining pressure ratio when NF density ranges from $24 / \mathrm{m}$ to $72 / \mathrm{m}$ and injection rate is $2.0 \times 10^{-6} \mathrm{~m}^{3} / \mathrm{s}$. 
Figure 22 demonstrates the influence of NF density on crack distribution under different CPRs. When NF density was relatively low $(\rho=24 / \mathrm{m})$, it was TCRM that mainly distributed both at the border of SRV and around the injection hole. SCNF only initiated in concentration area of TCRM, and no intersection or coalescence was found between the two. Under this condition, NF density was low and the strength of the rock formation itself was enough, which stopped HFN from propagating to areas far away from the injection hole. With the increase in NF density $(\rho=36 / \mathrm{m}$ or $48 / \mathrm{m})$, TCRMs still dominated in number around the injection hole. Since the increase of NF density led to significant growth in the number of cracks caused by natural fracture in HFN, SCNF mainly distributed at the border of the SRV. When NF density reached a high level $(\rho=60 / \mathrm{m}$ or $72 / \mathrm{m})$, SCNF became dominant, both at the border of the SRV and around the injection hole. TCRM was only sparsely distributed in HFN, but the number of these cracks was still far more than that of SCRM and TCNF.

Figure 23 demonstrates the incremental accumulation of TCRM, SCRM, TCNF, and SCNF under different CPRs during fracturing process. In the rock formations with the same NF densities, the total number of cracks under $S_{H}: S_{h}=10: 10$ was less than that in the other two CPRs. The results suggested that as the CPR approached 1.0, it became more difficult for the fracturing treatment to form rocks. When $\rho=24 / \mathrm{m}$, TCRM had the most value under all three CPRs. With an increase of NF density $(\rho=36 / \mathrm{m})$, SCNF values grew gradually and reached roughly an equal level with TCRM value. When $\rho \geq 48 / \mathrm{m}$, the SCNF value overtook TCRM value and became dominant among different crack types. The higher the NF density, the bigger of the gap between the value of SCNF and those of the other crack types. The value of TCNF also grew gradually with the increase in NF density. When $\rho=72 / \mathrm{m}$, the SCNF value almost doubled TCRM value. In particular, NF density and confining pressure had little influence on the SCRM value.

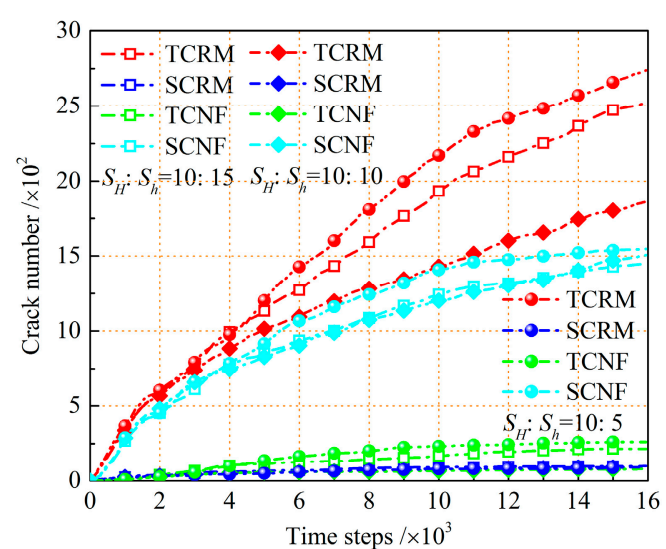

(a)

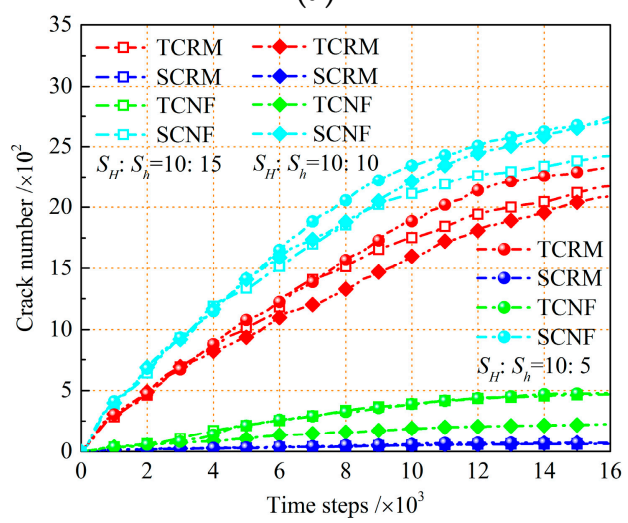

(c)

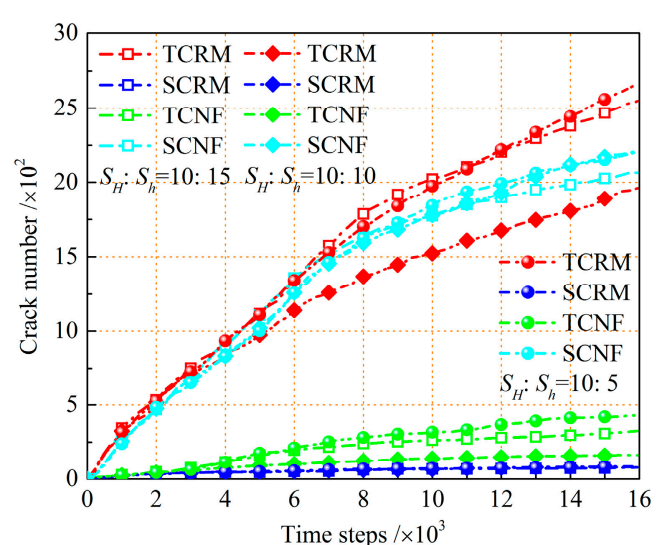

(b)

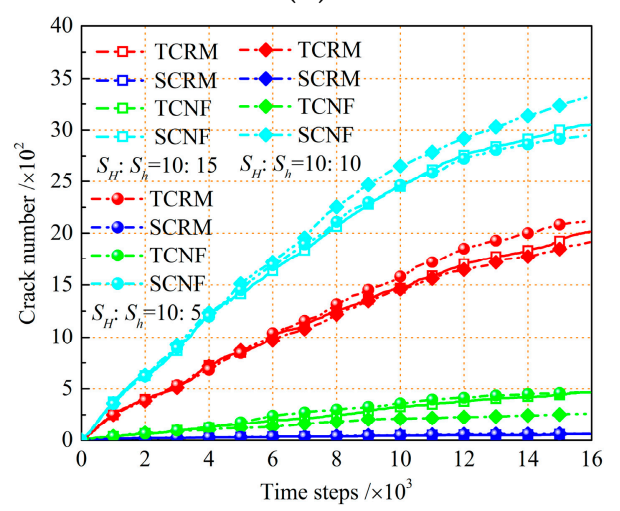

(d)

Figure 23. Cont. 


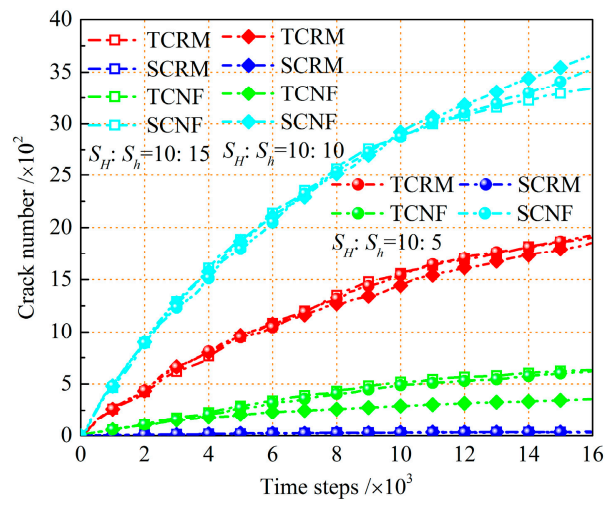

(e)

Figure 23. Incremental accumulation of TCRM, SCRM, TCNF, and SCNF in various NF densities when injection rate is $2.0 \times 10^{-6} \mathrm{~m}^{3} / \mathrm{s}$; (a) $\rho=24 / \mathrm{m}$; (b) $\rho=36 / \mathrm{m}$; (c) $\rho=48 / \mathrm{m}$; (d) $\rho=60 / \mathrm{m}$; and (e) $\rho=72 / \mathrm{m}$.

The fitting envelope curves reflect the relationship between NF density and the total number of cracks under different CPRs are shown in Figure 24 and Table 6. Figure 24 reveals an exponential relationship between the total number of cracks and NF density. When NF density was relatively low $(\rho=24 / \mathrm{m}$ or $36 / \mathrm{m})$, different CPRs resulted in large differences in the total number of cracks, which reached the maximum level when $S_{H}: S_{h}=10: 5$. The differences in the total number of cracks under different CPRs were gradually narrowed with an increase of NF density $(\rho \geq 36 / \mathrm{m})$. In other words, the variance of CPR had little influence on the change in the total number of cracks in rock formations with a high NF density.

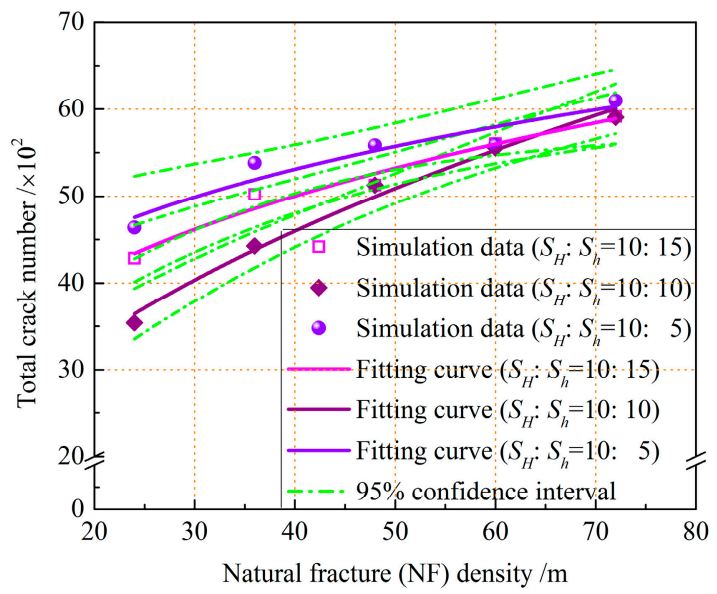

Figure 24. Variation of total number of cracks with NF density under different confining pressure ratios and injection rate is $2.0 \times 10^{-6} \mathrm{~m}^{3} / \mathrm{s}$.

Table 6. Fitting curve equations of total number of cracks under different confining pressure ratios.

\begin{tabular}{ccc}
\hline Confining Pressure Ratios & Fitting Curve Equations & R-Squared \\
\hline$S_{H}: S_{h}=10: 15$ & $y=17.90 x^{0.27}$ & 0.96 \\
$S_{H}: S_{h}=10: 10$ & $y=8.58 x^{0.46}$ & 0.98 \\
$S_{H}: S_{h}=10: 5$ & $y=23.86 x^{0.21}$ & 0.88 \\
\hline
\end{tabular}




\subsection{Considering Injection Rate}

In this section, the influence of NF density on HFN propagation under different injection rates: $2.0 \times 10^{-6} \mathrm{~m}^{3} / \mathrm{s}, 2.5 \times 10^{-6} \mathrm{~m}^{3} / \mathrm{s}$, and $3.0 \times 10^{-6} \mathrm{~m}^{3} / \mathrm{s}$, was investigated, and all required parameters were adopted from Tables 1-3. Figure 25 demonstrates the influence of NF density on injection pressure under different injection rates. CAIP was minimum under the injection rate of $2.0 \times 10^{-6} \mathrm{~m}^{3} / \mathrm{s}$, and with the increase of injection rate, the CAIP expanded gradually, especially along horizontal orientation. Meanwhile, the maximum injection pressure also grew with an injection rate increase. When the injection rate reached $3.0 \times 10^{-6} \mathrm{~m}^{3} / \mathrm{s}$, the injection pressure in the rock with $\rho=24 / \mathrm{m}$ became the biggest among all specimens and the CAIP also expanded with an increase of NF density. Meanwhile, under an injection rate of $3.0 \times 10^{-6} \mathrm{~m}^{3} / \mathrm{s}$, the expansions of CAIP in the horizontal and vertical orientation were almost the same as in the rock formation, with $\rho=72 / \mathrm{m}$.

The fitting strength envelope curves reflect the influence of NF density on breakdown pressure under different injection rates, and their corresponding equations are demonstrated in Figure 26 and Table 7, respectively. The results revealed a negative exponential relationship between breakdown pressure and NF density. When $\rho=24 / \mathrm{m}$, different injection rates resulted in the biggest difference in breakdown pressure. Particularly, under the injection rate of $3.0 \times 10^{-6} \mathrm{~m}^{3} / \mathrm{s}$, the breakdown pressure doubled under the injection rate of $2.0 \times 10^{-6} \mathrm{~m}^{3} / \mathrm{s}$. The difference in breakdown pressure gradually became smaller with an increase of NF density. This difference almost disappeared when $\rho=72 / \mathrm{m}$, which meant that the rock formation with this NF density was fragile.

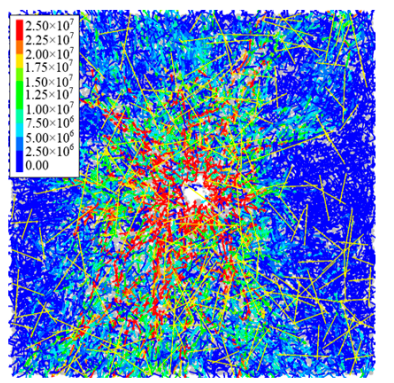

$2.0 \times 10^{-6} \mathrm{~m}^{3} / \mathrm{s}(\rho=24 / \mathrm{m})$

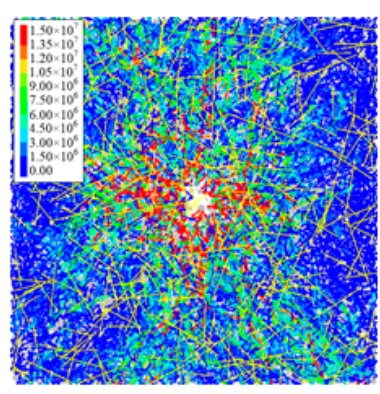

$2.0 \times 10^{-6} \mathrm{~m}^{3} / \mathrm{s}(\rho=36 / \mathrm{m})$

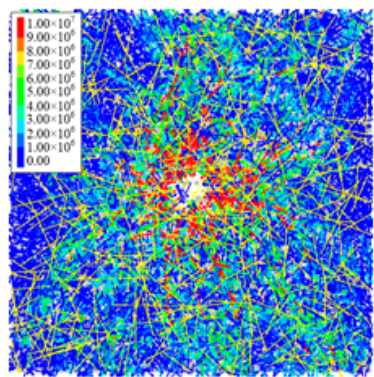

$2.0 \times 10^{-6} \mathrm{~m}^{3} / \mathrm{s}(\rho=48 / \mathrm{m})$

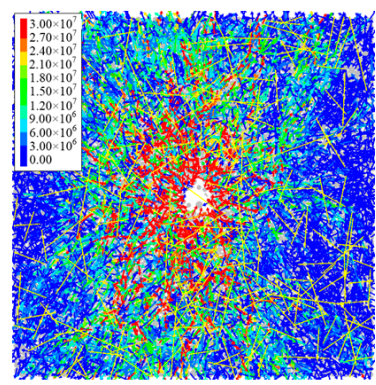

$$
2.5 \times 10^{-6} \mathrm{~m}^{3} / \mathrm{s}(\rho=24 / \mathrm{m})
$$

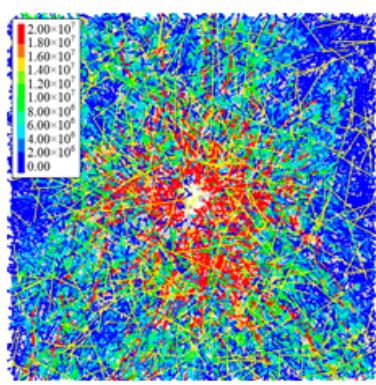

$2.5 \times 10^{-6} \mathrm{~m}^{3} / \mathrm{s}(\rho=36 / \mathrm{m})$

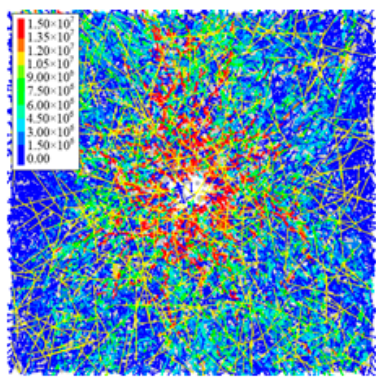

$2.5 \times 10^{-6} \mathrm{~m}^{3} / \mathrm{s}(\rho=48 / \mathrm{m})$

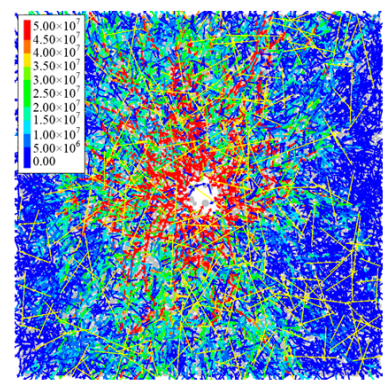

$3.0 \times 10^{-6} \mathrm{~m}^{3} / \mathrm{s}(\rho=24 / \mathrm{m})$

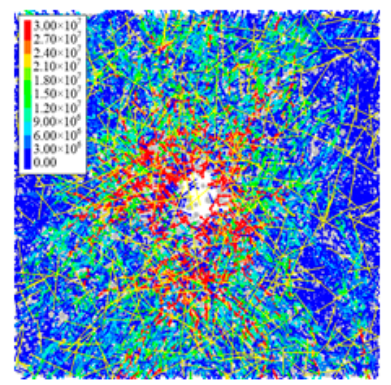

$3.0 \times 10^{-6} \mathrm{~m}^{3} / \mathrm{s}(\rho=36 / \mathrm{m})$

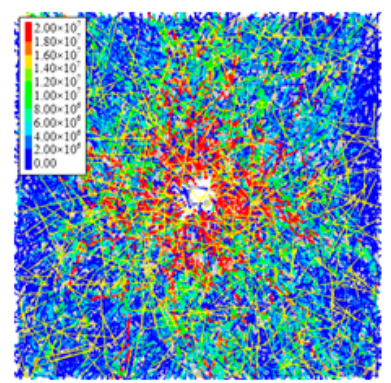

$3.0 \times 10^{-6} \mathrm{~m}^{3} / \mathrm{s}(\rho=48 / \mathrm{m})$

Figure 25. Cont. 


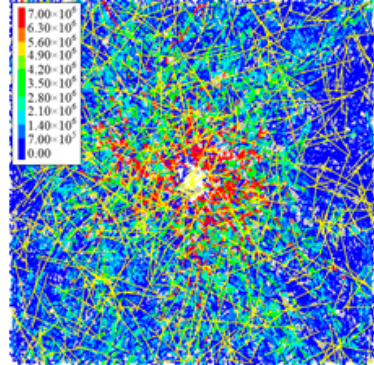

$2.0 \times 10^{-6} \mathrm{~m}^{3} / \mathrm{s}(\rho=60 / \mathrm{m})$

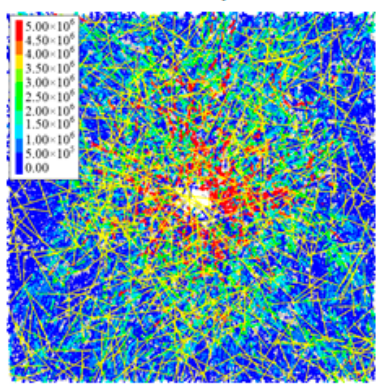

$2.0 \times 10^{-6} \mathrm{~m}^{3} / \mathrm{s}(\rho=72 / \mathrm{m})$

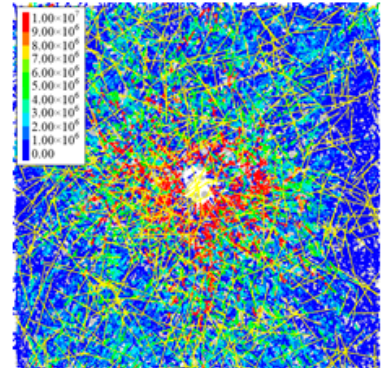

$2.5 \times 10^{-6} \mathrm{~m}^{3} / \mathrm{s}(\rho=60 / \mathrm{m})$

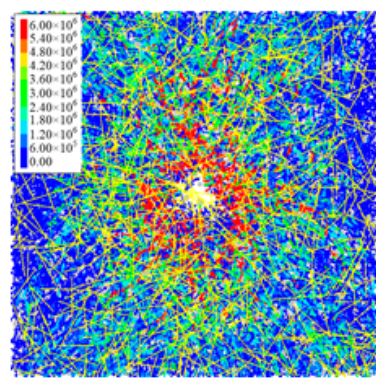

$2.5 \times 10^{-6} \mathrm{~m}^{3} / \mathrm{s}(\rho=72 / \mathrm{m})$

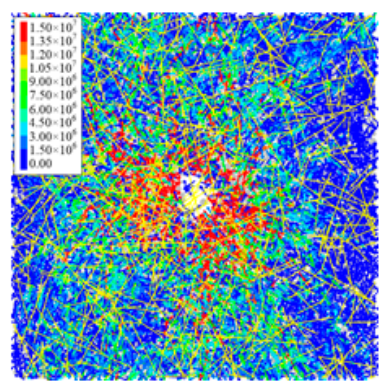

$3.0 \times 10^{-6} \mathrm{~m}^{3} / \mathrm{s}(\rho=60 / \mathrm{m})$

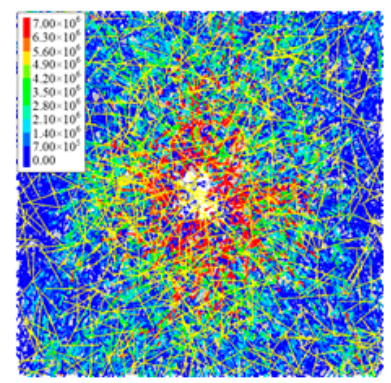

$3.0 \times 10^{-6} \mathrm{~m}^{3} / \mathrm{s}(\rho=72 / \mathrm{m})$

Figure 25. Change of injection pressure with injection rate when NF density ranges from $24 / \mathrm{m}$ to $72 / \mathrm{m}$ and $S_{H}: S_{h}=10: 5$.

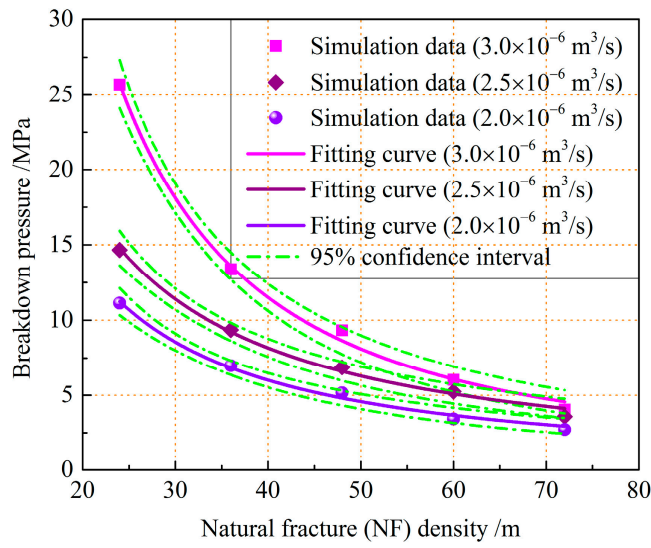

Figure 26. Variation of breakdown pressure with NF density under different injection rates and confining pressure ratio is $S_{H}: S_{h}=10: 5$.

Table 7. Fitting curve equations of breakdown pressure under different injection rates.

\begin{tabular}{ccc}
\hline Injection Rates/m $\mathbf{m}^{\mathbf{3}} \mathbf{s}^{-\mathbf{1}}$ & Fitting Curve Equations & $\boldsymbol{R}$-Squared \\
\hline $2.0 \times 10^{-6}$ & $y=3813 x^{-1.27}$ & 0.99 \\
$2.5 \times 10^{-6}$ & $y=592 x^{-1.16}$ & 0.98 \\
$3.0 \times 10^{-6}$ & $y=548 x^{-1.22}$ & 0.98 \\
\hline
\end{tabular}

Figure 27 reveals the influence of NF density on the crack distribution under different injection rates. During the primary stage of fluid injection, all injection rates were high and exceeded the threshold of crack initiation. Therefore, although injection rates were different, the type, number, and distribution of cracks around injection holes on the rock formations were similar. With further propagation, however, the distribution of cracks under different injection rates tended to be different. The area of crack propagation under the minimum injection rate of $2.0 \times 10^{-6} \mathrm{~m}^{3} / \mathrm{s}$ also became 
the smallest one. Nevertheless, when NF density was high enough $(\rho \geq 60 / \mathrm{m})$, this phenomenon disappeared and crack propagation areas under all injection rates tended to be similar. Additionally, the injection rate had no influence on the percentage of different types of cracks. From high NF density to low NF density, the dominant values for crack types also shifted from TCRM to SCNF.

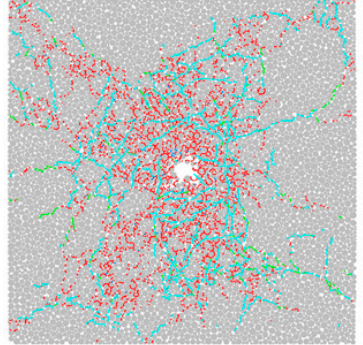

$2.0 \times 10^{-6} \mathrm{~m}^{3} / \mathrm{s}(\rho=24 / \mathrm{m})$

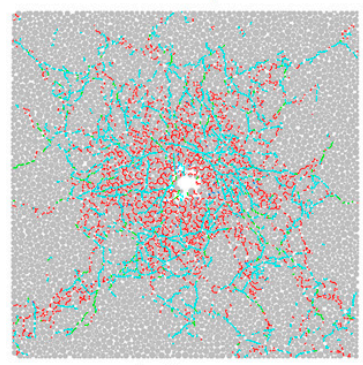

$2.0 \times 10^{-6} \mathrm{~m}^{3} / \mathrm{s}(\rho=36 / \mathrm{m})$

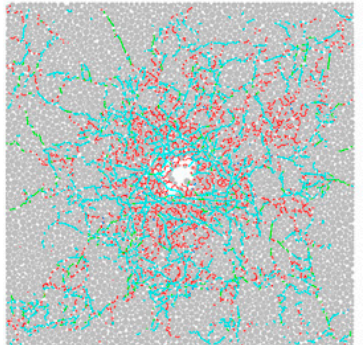

$2.0 \times 10^{-6} \mathrm{~m}^{3} / \mathrm{s}(\rho=48 / \mathrm{m})$

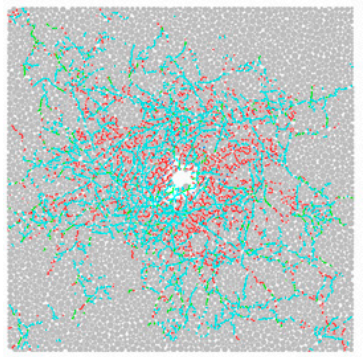

$2.0 \times 10^{-6} \mathrm{~m}^{3} / \mathrm{s}(\rho=60 / \mathrm{m})$

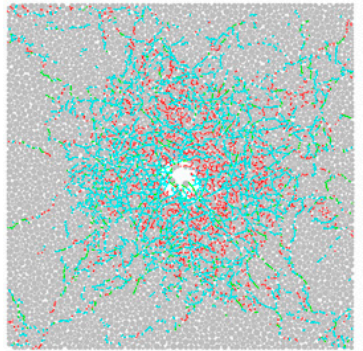

$2.0 \times 10^{-6} \mathrm{~m}^{3} / \mathrm{s}(\rho=72 / \mathrm{m})$

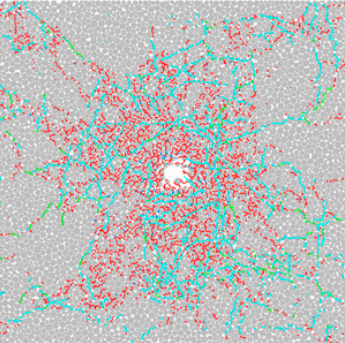

$2.5 \times 10^{-6} \mathrm{~m}^{3} / \mathrm{s}(\rho=24 / \mathrm{m})$

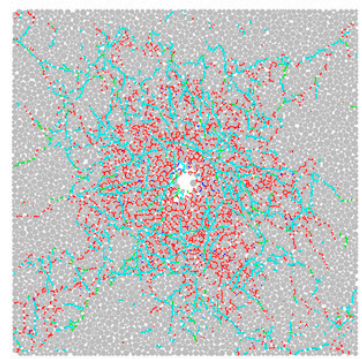

$2.5 \times 10^{-6} \mathrm{~m}^{3} / \mathrm{s}(\rho=36 / \mathrm{m})$

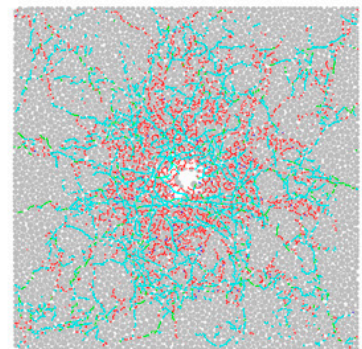

$2.5 \times 10^{-6} \mathrm{~m}^{3} / \mathrm{s}(\rho=48 / \mathrm{m})$

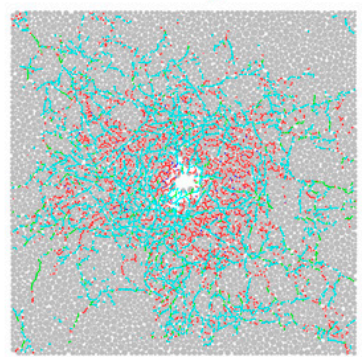

$2.5 \times 10^{-6} \mathrm{~m}^{3} / \mathrm{s}(\rho=60 / \mathrm{m})$

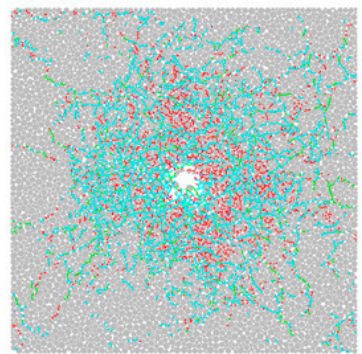

$2.5 \times 10^{-6} \mathrm{~m}^{3 / \mathrm{s}}(\rho=72 / \mathrm{m})$

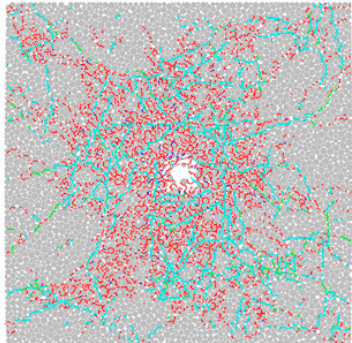

$3.0 \times 10^{-6} \mathrm{~m}^{3} / \mathrm{s}(\rho=24 / \mathrm{m})$

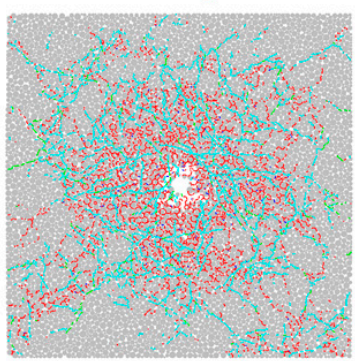

$3.0 \times 10^{-6} \mathrm{~m}^{3} / \mathrm{s}(\rho=36 / \mathrm{m})$

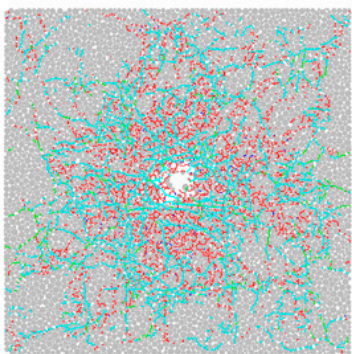

$3.0 \times 10^{-6} \mathrm{~m}^{3} / \mathrm{s}(\rho=48 / \mathrm{m})$

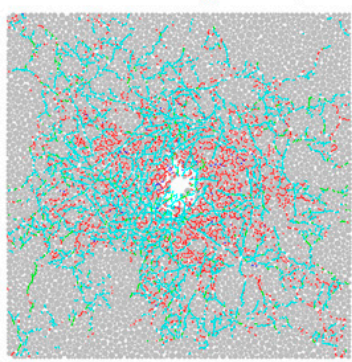

$3.0 \times 10^{-6} \mathrm{~m}^{3} / \mathrm{s}(\rho=60 / \mathrm{m})$

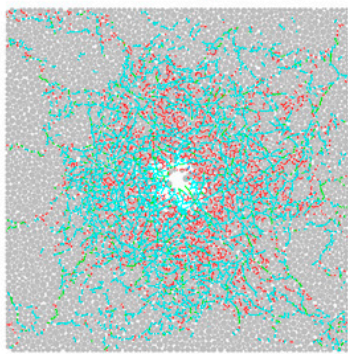

$3.0 \times 10^{-6} \mathrm{~m}^{3} / \mathrm{s}(\rho=72 / \mathrm{m})$

Figure 27. Change of crack distribution with injection rate when NF density ranges from $24 / \mathrm{m}$ to $72 / \mathrm{m}$ and confining pressure ratio is $S_{H}: S_{h}=10: 5$. 
Figure 28 demonstrates the incremental accumulation of TCRM, SCRM, TCNF, and SCNF under different injection rates. In rock formations with $\rho=24 / \mathrm{m}$, TCRM always predominated, regardless of the changes in injection rate. When NF density increased from $24 / \mathrm{m}$ to $48 / \mathrm{m}$ or $60 / \mathrm{m}$, larger injection rates led to more TCRM and SCNF, and SCNF dominated TCRM in value under relatively high injection rates. When NF density reached the maximum value $(\rho=72 / \mathrm{m}), \mathrm{SCNF}$ almost doubled TCRM in value. Similarly, the changes of NF density and injection rate had little influence on the value of SCRM and TCNF.

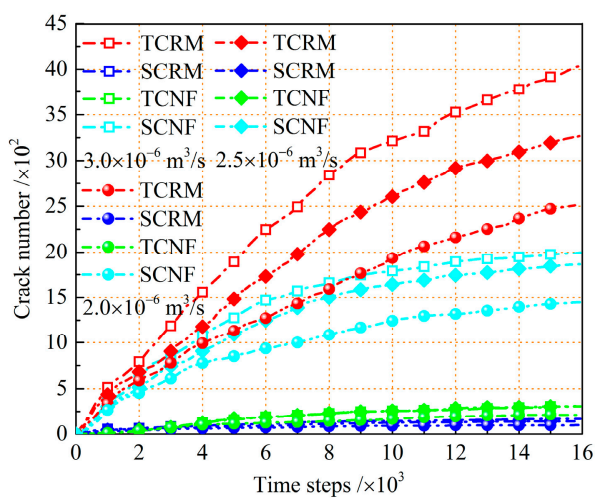

(a)

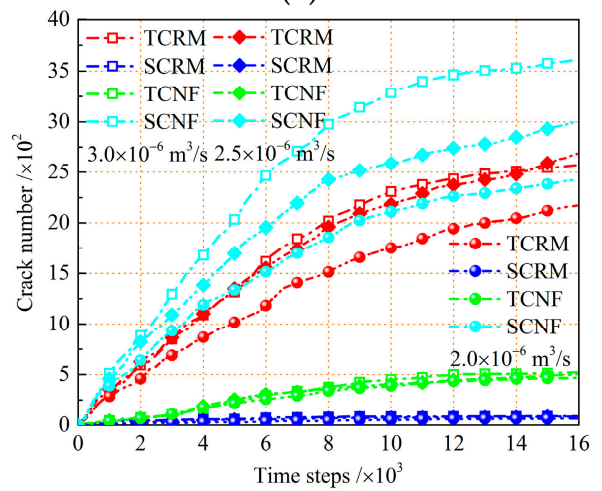

(c)

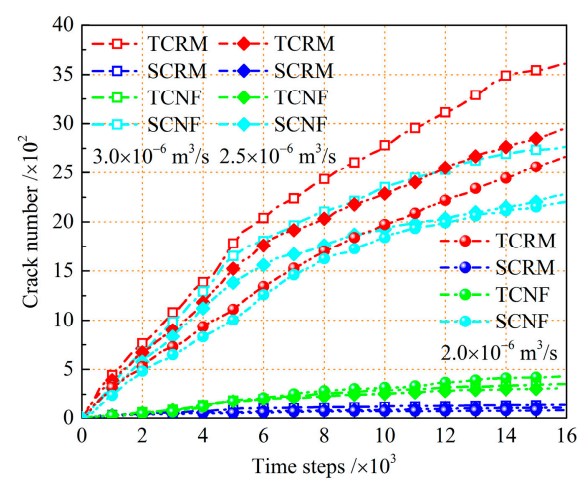

(b)

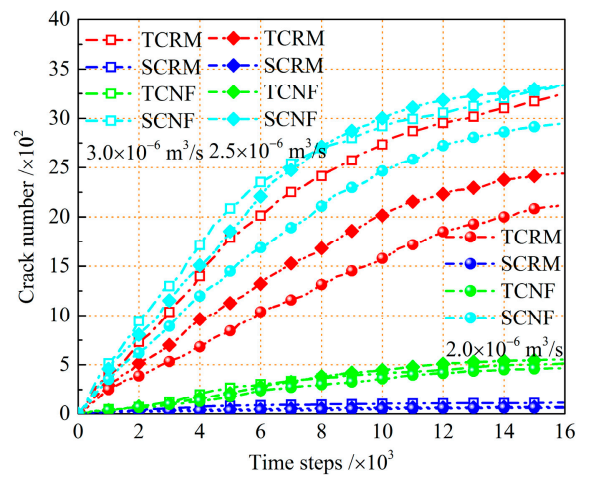

(d)

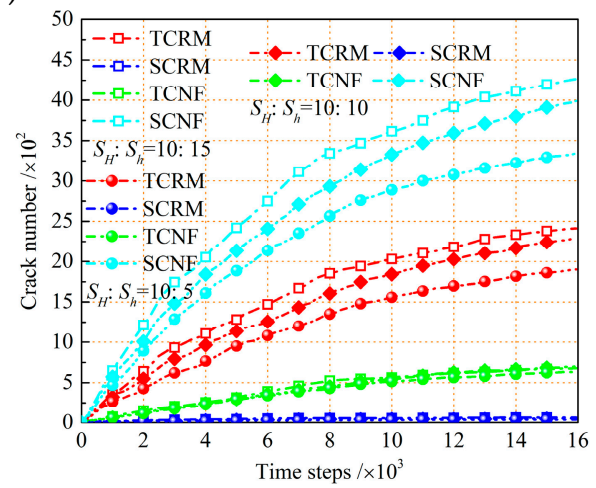

(e)

Figure 28. Incremental accumulation of TCRM, SCRM, TCNF, and SCNF in various NF densities when the confining pressure ratio is $S_{H}: S_{h}=10: 5$; (a) $\rho=24 / \mathrm{m}$; (b) $\rho=36 / \mathrm{m}$; (c) $\rho=48 / \mathrm{m}$; (d) $\rho=60 / \mathrm{m}$; and (e) $\rho=72 / \mathrm{m}$.

The fitting envelope curves reflect the relationship between NF density and total number of cracks under different injection rates are shown in Figure 29 and Table 8, respectively. Figure 29 reveals an increase in the total number of cracks with higher injection rates and NF density. The increase in injection rates can result in a linear growth of the crack number in the fracturing process. 


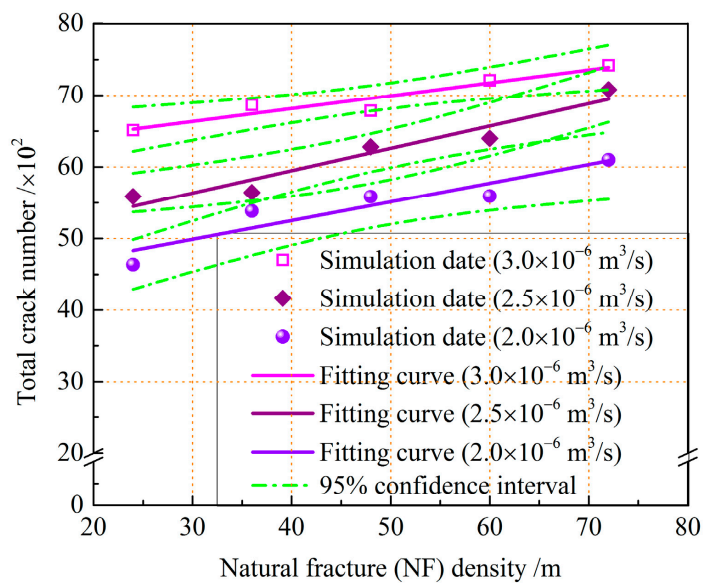

Figure 29. Variation of the total number of cracks with NF density under different injection rates and confining pressure ratio is $S_{H}: S_{h}=10: 5$.

Table 8. Fitting curve equations of the total number of cracks under different injection rates.

\begin{tabular}{ccc}
\hline Injection Rates/m $\mathbf{m}^{\mathbf{3}} \cdot \mathbf{s}^{-\mathbf{1}}$ & Fitting Curve Equations & $\boldsymbol{R}$-Squared \\
\hline $2.0 \times 10^{-6}$ & $y=0.18 x+61$ & 0.87 \\
$2.5 \times 10^{-6}$ & $y=0.31 x+47$ & 0.91 \\
$3.0 \times 10^{-6}$ & $y=0.26 x+42$ & 0.83 \\
\hline
\end{tabular}

\section{Discussion}

\subsection{Particle Size}

In Section 5, the size of the model was $1.0 \times 1.0 \mathrm{~m}$, and the average particle size was $9 \mathrm{~mm}$. During the NF process in fractured rock formation, the sensitivity of the particle size was analyzed to determine the influence on HFN. In the $1.0 \times 1.0 \mathrm{~m}$ model, five particle sizes of $4.50(-50 \%)$, $6.25(-25 \%), 9.0,11.25(+25 \%)$ and $13.50(+50 \%) \mathrm{mm}$ were selected for NF examinations.

Figure 30 demonstrates the influence of different particle sizes on injection pressure and crack distribution of the model when the NF density is $48 / \mathrm{m}$ and $S_{H}: S_{h}=10: 5$. When the model size remained unchanged, the variance in particle size had little influence on the injection pressure, while CAIP still developed along the maximum principal stress orientation. Additionally, the distribution of maximum injection pressures was essentially similar. Since the variance of particle size changed the number of contacts in the model, there was some difference in the quantity of cracks. Particle size had little influence, however, on the trend of fracture propagation and the proportion of crack types.

Ding [49] suggested that when the ratio of model size $(L)$ to the average particle size $(R)$ is small, the difference of particle size would lead to a bigger variance in macro-mechanical behavior of the model. When $L / R \geq 50$, however, the variance of particle size has limited influence on the macro-mechanical behavior of the model. In this study, the average particle size was from 4.50 to $13.50 \mathrm{~mm}$ and $L / R$ ratio was bigger than 50 . These figures show that the particle size had a limited effect on mechanical behavior when the $L / R$ ratio was greater than 50 , which agrees well with published results [49]. 
Particle size/ mm

4.50

6.25

9.0

11.25

13.50
Injection pressure $/ \mathrm{MPa}$
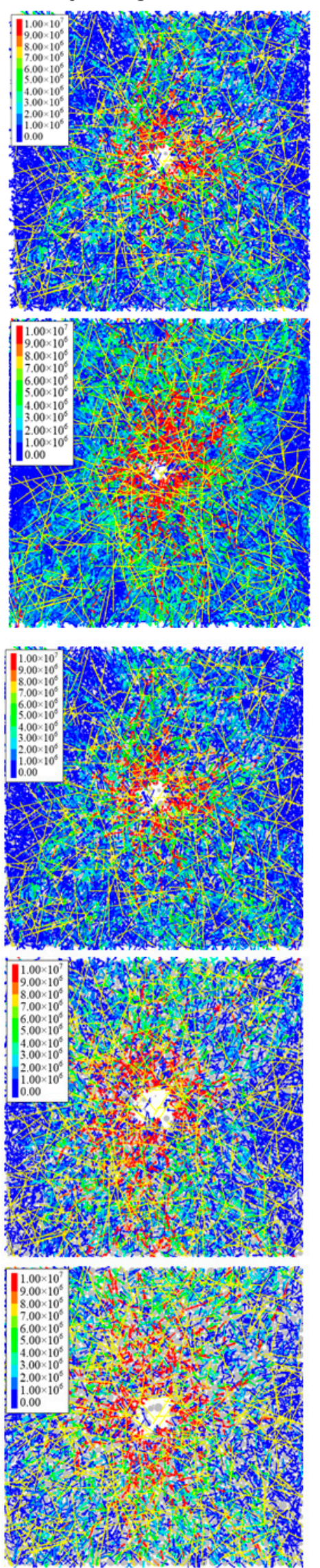

Crack distribution
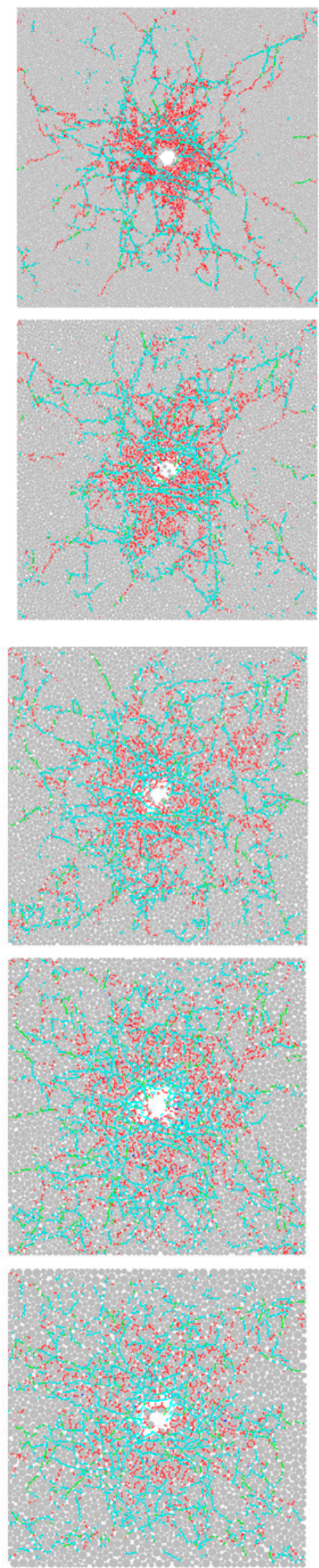

Figure 30. Change of injection pressure and crack distribution with particle size when NF density is $48 / \mathrm{m}$ and $S_{H}: S_{h}=10: 5$. 


\subsection{Model Size}

In order to study the influence of model size on the effect of fractures, six sizes of 1.0, 10, 25, 50, 75 and $100 \mathrm{~m}$ were selected. Figure 31 shows the influence of different model sizes on the injection pressure and crack distribution of the model when the NF density was $48 / \mathrm{m}$ and $S_{H}: S_{h}=10: 5$. The variance in model size had a remarkable effect on injection pressure and crack distribution. The injection pressure greatly increased with the increase in model size. When the model size reached $10 \mathrm{~m}$, cracks appeared in the NF of rock formations. Thereafter, cracks gradually appeared in the rock matrix. Under the premise of different model sizes, however, CAIP and fractures still developed along the vertical orientation, i.e., the maximum principal stress orientation.

Based on many numerical simulation models, our explanation for the discrepancy among the results was that our model was larger in size than the models in Section 5, and that the size of the model can influence the value of the injection pressure and crack distribution, which is our next subject of research.

Another reason was the differentiation of parameters input in the model. In Section 4, the input parameters were calibrated in line with physical experiments at the laboratory scale. If these parameters were applied to a model of a larger size, size effects and anisotropy would inevitably appear, leading to different injection pressures and fracture distributions. Thus, it is necessary to study the size effects and anisotropy before the proposed model goes through HF under different sizes in order to determine REV. This will be our next topic of research.
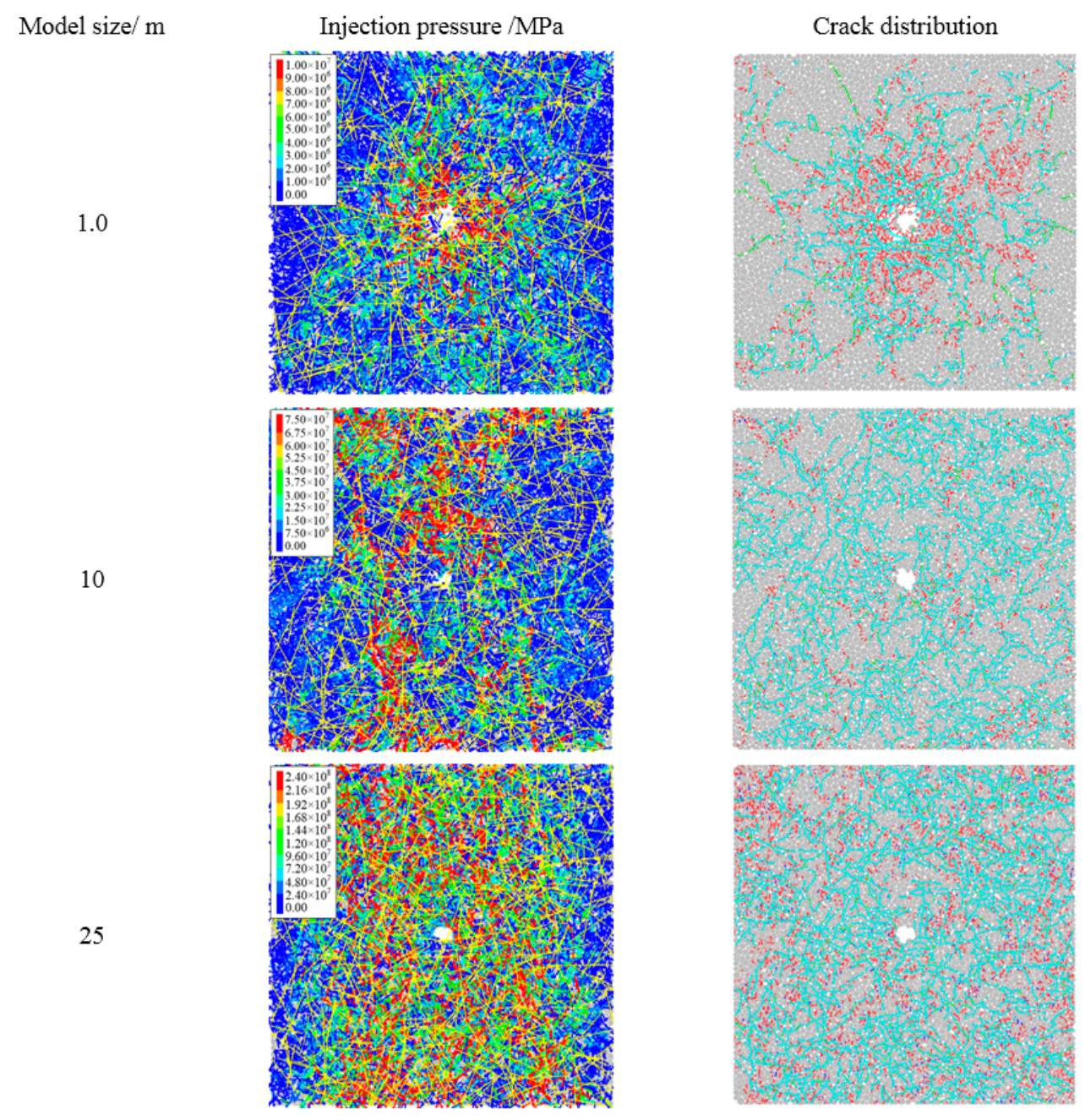

Figure 31. Cont. 
50

75

100
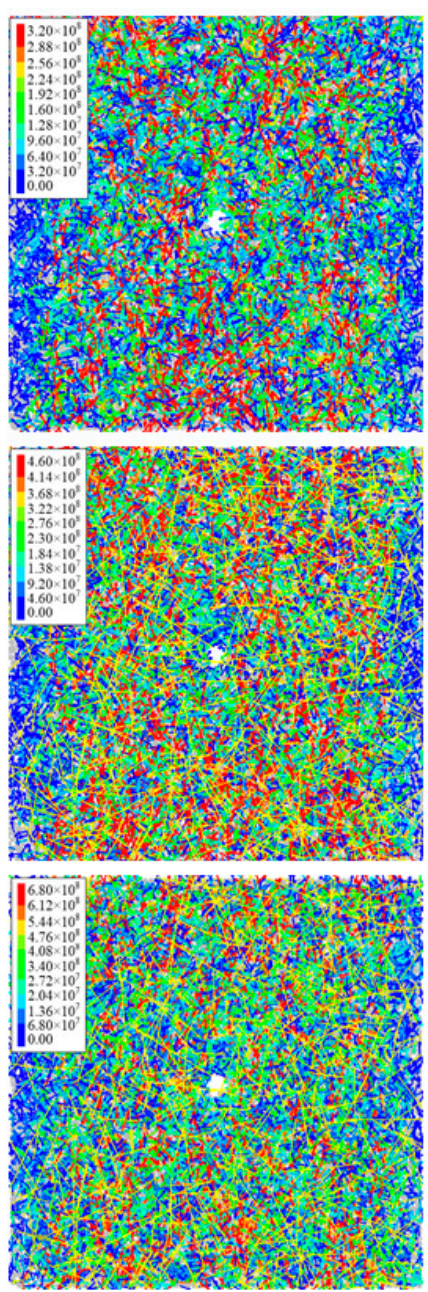
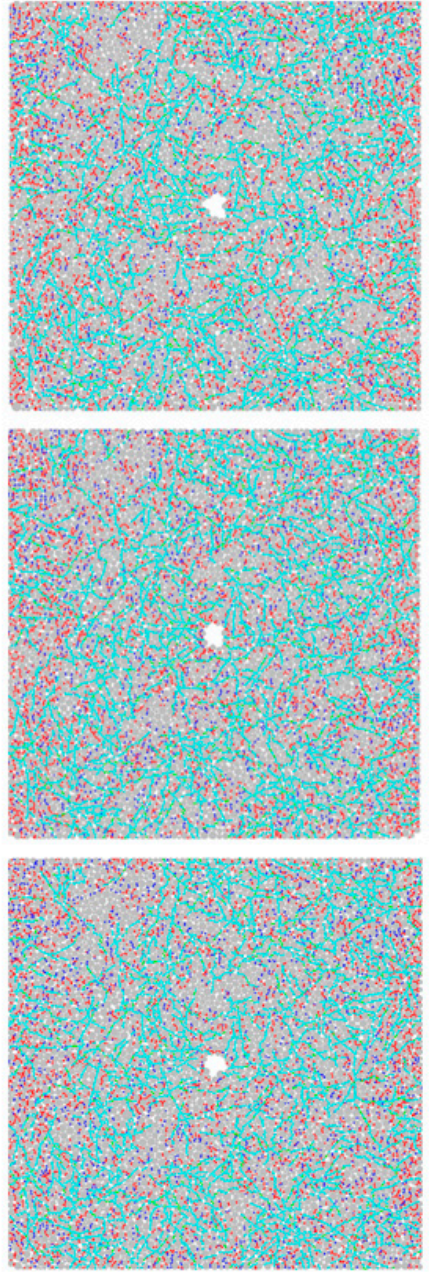

Figure 31. Change in injection pressure and crack distribution with model size when NF density is $48 / \mathrm{m}$ and $S_{H}: S_{h}=10: 5$.

\section{Conclusions}

A series of numerical modellings for hydraulic fracturing were performed using a modified coupled hydro-mechanical model in SRM to investigate the effect of NF density on HFN propagation. In addition, two key factors-CPR and injection rate-were also analyzed and the following conclusions could be drawn:

(1) Natural fracturing density had a significant influence on SRV, CAIP, and the numbers of different types of cracks in the HFN forming process. For a specimen with a high NF density, hydraulic fracturing often resulted in a larger SRV, larger CAIP, and more SCNF and TCNF. The number of TCRM, however, decreased gradually with an increase in NF density, and SCRM is almost immune to NF density.

(2) In the fracturing process, it was the CPR that controlled the differences in HFN propagation orientation and breakdown pressure. With an increase in NF density, the differences gradually narrowed. When confining pressures were the same in the horizontal and vertical orientations, the number of cracks initiated in the HFN were minimal.

(3) A difference in injection rate can lead to a greater variance in the gradient of injection pressure in rock formations. In addition, the change in injection rate can only influence the HFN in areas far away from the injection hole, and this influence gradually disappeared with an increase in NF density $(\rho \geq 60 / \mathrm{m})$. 
(4) Regardless of the CPR and injection rate, the percentages of different crack types in HFN were principally controlled by NF density. In rock formations with a high enough NF density $(\rho \geq 72 / \mathrm{m})$, the total number of cracks under different CPRs and injection rates were similar, which was conducive to parameter optimization in fracture treatment.

It is crucial for a reservoir stimulation to understand the effects of NF density on HFN propagation, as well as HF and NF interactions. Furthermore, the proposed model will cause scale effects and anisotropy, with an increase in size-this topic will be investigated in future studies.

Acknowledgments: This research is supported by the Fundamental Research Funds for the Central Universities (2017BSCXB44), Postgraduate Research \& Practice Innovation Program of Jiangsu Province (KYCX17_1555) and a Project Funded by the Priority Academic Program Development of Jiangsu Higher Education Institutions (PAPD).

Author Contributions: Zhaohui Chong and Xuehua Li designed the theoretical framework and wrote the manuscript; Zhaohui Chong and Ji Zhang conducted the hydraulic fracturing simulations and analyzed the data; Xiangyu Chen and Jingzheng Lu conducted the simulation in situ tests. All authors have read and approved the final manuscript.

Conflicts of Interest: The authors declare that they have no conflicts of interest.

\section{References}

1. Torres, L.; Yadav, O.P.; Khan, E. A review on risk assessment techniques for hydraulic fracturing water and produced water management implemented in onshore unconventional oil and gas production. Sci. Total Environ. 2016, 539, 478-493. [CrossRef] [PubMed]

2. Abdollahipour, A.; Fatehi Marji, M.; Yarahmadi Bafghi, A.; Gholamnejad, J. DEM simulation of confining pressure effects on crack opening displacement in hydraulic fracturing. Int. J. Min. Sci. Technol. 2016, 26, 557-561. [CrossRef]

3. Zeng, Q.; Yao, J. Numerical simulation of fracture network generation in naturally fractured reservoirs. J. Nat. Gas Sci. Eng. 2016, 30, 430-443. [CrossRef]

4. Ren, L.; Su, Y.; Zhan, S.; Hao, Y.; Meng, F.; Sheng, G. Modeling and simulation of complex fracture network propagation with SRV fracturing in unconventional shale reservoirs. J. Nat. Gas Sci. Eng. 2016, 28, 132-141. [CrossRef]

5. Huang, B.; Liu, C.; Fu, J.; Guan, H. Hydraulic fracturing after water pressure control blasting for increased fracturing. Int. J. Rock Mech. Min. 2011, 48, 976-983. [CrossRef]

6. Puller, J.W.; Mills, K.W.; Jeffrey, R.G.; Walker, R.J. In-situ stress measurements and stress change monitoring to monitor overburden caving behaviour and hydraulic fracture pre-conditioning. Int. J. Min. Sci. Technol. 2016, 26, 103-110. [CrossRef]

7. Weng, X.; Kresse, O.; Chuprakov, D.; Cohen, C.E.; Prioul, R.; Ganguly, U. Applying complex fracture model and integrated workflow in unconventional reservoirs. J. Petrol. Sci. Eng. 2014, 124, 468-483. [CrossRef]

8. Guo, J.; Liu, Y. A comprehensive model for simulating fracturing fluid leakoff in natural fractures. J. Nat. Gas Sci. Eng. 2014, 21, 977-985. [CrossRef]

9. Cheng, W.; Jin, Y.; Chen, M. Reactivation mechanism of natural fractures by hydraulic fracturing in naturally fractured shale reservoirs. J. Nat. Gas Sci. Eng. 2015, 27, 1357-1365. [CrossRef]

10. Renshaw, C.E.; Pollard, D.D. An experimentally verified criterion for propagation across unbounded frictional interfaces in brittle, linear elastic materials. Int. J. Rock Mech. Min. 1995, 32, 234-249. [CrossRef]

11. Gu, H.; Weng, X. Criterion for fractures crossing frictional interfaces at non-orthogonal angles. In Proceedings of the 44th US Rock Mechanics Symposium and 5th US-Canada Rock Mechanics Symposium, Salt Lake City, UT, USA, 27-30 June 2010.

12. Anderson, G.D. Effects of friction on hydraulic fracture growth near unbonded interfaces in rocks. Soc. Pet. Eng. J. 1981, 21, 21-29. [CrossRef]

13. Weng, X. Modeling of complex hydraulic fractures in naturally fractured formation. J. Unconv. Oil Gas Resour. 2015, 9, 114-135. [CrossRef]

14. Zou, Y.; Zhang, S.; Ma, X.; Zhou, T.; Zeng, B. Numerical investigation of hydraulic fracture network propagation in naturally fractured shale formations. J. Struct. Geol. 2016, 84, 1-13. [CrossRef] 
15. Wu, Y.; Li, X. Numerical simulation of the propagation of hydraulic and natural fracture using Dijkstra's algorithm. Energies 2016, 9, 519. [CrossRef]

16. Marina, S.; Derek, I.; Mohamed, P.; Yong, S.; Imo-Imo, E.K. Simulation of the hydraulic fracturing process of fractured rocks by the discrete element method. Environ. Earth Sci. 2015, 73, 8451-8469. [CrossRef]

17. Fu, P.; Johnson, S.M.; Carrigan, C.R. An explicitly coupled hydro-geomechanical model for simulating hydraulic fracturing in arbitrary discrete fracture networks. Int. J. Numer. Anal. Methods Geomech. 2013, 37, 2278-2300. [CrossRef]

18. Hou, B.; Chen, M.; Cheng, W.; Diao, C. Investigation of hydraulic fracture networks in shale gas reservoirs with random fractures. Arab. J. Sci. Eng. 2016, 41, 2681-2691. [CrossRef]

19. Liu, R.; Li, B.; Jiang, Y.; Huang, N. Review: Mathematical expressions for estimating equivalent permeability of rock fracture networks. Hydrogeol. J. 2016, 24, 1623-1649. [CrossRef]

20. Huang, N.; Jiang, Y.; Li, B.; Liu, R. A numerical method for simulating fluid flow through 3-D fracture networks. J. Nat. Gas Sci. Eng. 2016, 33, 1271-1281. [CrossRef]

21. Meyer, B.R.; Bazan, L.W. A discrete fracture network model for hydraulically induced fractures: Theory, parametric and case studies. In Proceedings of the SPE Hydraulic Fracturing Technology Conference: Society of Petroleum Engineers, Denver, CO, USA, 30 October-2 November 2011.

22. Weng, X.; Kresse, O.; Cohen, C.E.; Wu, R.; Gu, H. Modeling of hydraulic-fracture-network propagation in a naturally fractured formation. SPE Prod. Oper. 2011, 26, 368-380. [CrossRef]

23. Ganis, B.; Mear, M.E.; Sakhaee-Pour, A.; Wheeler, M.F.; Wick, T. Modeling fluid injection in fractures with a reservoir simulator coupled to a boundary element method. Comput. Geosci. 2014, 18, 613-624. [CrossRef]

24. Biryukov, D.; Kuchuk, F.J. Pressure transient behavior of horizontal wells intersecting multiple hydraulic fractures in naturally fractured reservoirs. Transp. Porous Media 2015, 110, 369-408. [CrossRef]

25. Liu, P.; Liu, F.; She, C.; Zhao, L.; Luo, Z.; Guan, W.; Li, N. Multi-phase fracturing fluid leakoff model for fractured reservoir using extended finite element method. J. Nat. Gas Sci. Eng. 2016, 28, 548-557. [CrossRef]

26. Wang, X.; Shi, F.; Liu, H.; Wu, H. Numerical simulation of hydraulic fracturing in orthotropic formation based on the extended finite element method. J. Nat. Gas Sci. Eng. 2016, 33, 56-69. [CrossRef]

27. Yan, F.; Lin, B.; Zhu, C.; Shen, C.; Zou, Q.; Guo, C.; Liu, T. A novel ECBM extraction technology based on the integration of hydraulic slotting and hydraulic fracturing. J. Nat. Gas Sci. Eng. 2015, 22, 571-579. [CrossRef]

28. Yang, T.; Zhu, W.; Yu, Q.; Liu, H. The role of pore pressure during hydraulic fracturing and implications for groundwater outbursts in mining and tunnelling. Hydrogeol. J. 2011, 19, 995-1008. [CrossRef]

29. Eshiet, K.I.; Sheng, Y.; Ye, J. Microscopic modelling of the hydraulic fracturing process. Environ. Earth Sci. 2013, 68, 1169-1186. [CrossRef]

30. Deng, S.; Li, H.; Ma, G.; Huang, H.; Li, X. Simulation of shale-proppant interaction in hydraulic fracturing by the discrete element method. Int. J. Rock Mech. Min. 2014, 70, 219-228. [CrossRef]

31. Mas Ivars, D.; Pierce, M.E.; Darcel, C.; Reyes-Montes, J.; Potyondy, D.O.; Young, R.P.; Cundall, P.A. The synthetic rock mass approach for jointed rock mass modelling. Int. J. Rock Mech. Min. 2011, 48, 219-244. [CrossRef]

32. Potyondy, D.O.; Cundall, P.A. A bonded-particle model for rock. Int. J. Rock Mech. Min. 2004, 41, $1329-1364$. [CrossRef]

33. Pierce, M.; Cundall, R.; Potyondy, D.; Mas Ivars, D. A synthetic rock mass model for jointed rock. In Rock Mechanics: Meeting Society's Challenges and Demands; Eberhardt, E., Stead, D., Morrison, T., Eds.; Taylor and Francis Group: London, UK, 2007; pp. 341-349.

34. Al-Busaidi, A.; Hazzard, J.; Young, R.P. Distinct element modeling of hydraulically fractured Lac du Bonnet granite. J. Geophys. Res. 2005, 110. [CrossRef]

35. Hazzard, J.F.; Young, R.P.; Oates, S.J. Numerical modeling of seismicity induced by fluid injection in a fractured reservoir. In Proceedings of the 5th North American Rock Mechanics Symposium, Toronto, ON, Canada, 7-10 July 2002.

36. Hökmark, H.; Lönnqvist, M.; Fälth, B. Thermal, Mechanical, Thermo-Mechanical and Hydro-Mechanical Evolution of the Rock at the Forsmark and Laxemar Sites: SKB TR1023, Svensk Kärnbränslehantering AB; Swedish Nuclear Fuel and Waste Management Co.: Stockholm, Sweden, 2010. 
37. Yoon, J.S.; Zang, A.; Stephansson, O. Numerical investigation on optimized stimulation of intact and naturally fractured deep geothermal reservoirs using hydro-mechanical coupled discrete particles joints model. Geothermics 2014, 52, 165-184. [CrossRef]

38. Zhao, X.; Young, R.P. Numerical modeling of seismicity induced by fluid injection in naturally fractured reservoirs. Geophysics 2011, 76, WC167-WC180. [CrossRef]

39. Zhou, J.; Zhang, L.; Pan, Z.; Han, Z. Numerical investigation of fluid-driven near-borehole fracture propagation in laminated reservoir rock using PFC 2D. J. Nat. Gas Sci. Eng. 2016, 36, 719-733. [CrossRef]

40. Zhu, H.; Yi, C.; Jiang, Y. Effect of fractures cross connection on fluid flow characteristics of mining-induced rock. Journal of China University of Mining\&Technology. J. China Univ. Min. Technol. 2015, 44, 24-28. (In Chinese)

41. Chong, Z.; Li, X.; Lu, J.; Chen, T.; Zhang, J.; Chen, X. Numerical investigation of acoustic emission events of argillaceous sandstones under confining pressure. Math. Probl. Eng. 2017, 2017, 1-16. [CrossRef]

42. Warpinski, N.R.; Teufel, L.W. Influence of geologic discontinuities on hydraulic fracture propagation. J. Pet. Technol. 1987, 39, 209-220. [CrossRef]

43. Blanton, T.L. Propagation of hydraulically and dynamically induced fractures in naturally fractured reservoirs. In Proceedings of the SPE15261 Presented at the SPE Unconventional Gas Technology Symposium, Louisville, KY, USA, 18-21 May 1986.

44. Gu, H.; Weng, X.; Lund, J.B.; Mack, M.G.; Ganguly, U.; Suarez-Rivera, R. Hydraulic fracture crossing natural fracture at nonorthogonal angles: A criterion and its validation. SPE Prod. Oper. 2012, 27, 20-26. [CrossRef]

45. Wang, T.; Zhou, W.; Chen, J.; Xiao, X.; Li, Y.; Zhao, X. Simulation of hydraulic fracturing using particle flow method and application in a coal mine. Int. J. Coal Geol. 2014, 121, 1-13. [CrossRef]

46. Fjar, E.; Holt, R.M.; Raaen, A.M.; Risnes, R.; Horsrud, P. Petroleum Related Rock Mechanics; Elsevier: Amsterdam, The Netherlands, 2008.

47. Zhang, B.; Li, X.; Zhang, Z.; Wu, Y.; Wu, Y.; Wang, Y. Numerical investigation of influence of in-situ stress ratio, injection rate and fluid viscosity on hydraulic fracture propagation using a distinct element approach. Energies 2016, 9, 140. [CrossRef]

48. Mayerhofer, M.J.; Lolon, E.; Warpinski, N.R.; Cipolla, C.L.; Walser, D.W.; Rightmire, C.M. What is stimulated reservoir volume? SPE Prod. Oper. 2010, 25, 89-98. [CrossRef]

49. Ding, X.; Zhang, L.; Zhu, H.; Zhang, Q. Effect of model scale and particle size distribution on PFC3D simulation results. Rock Mech. Rock Eng. 2014, 47, 2139-2156. [CrossRef] 